\title{
On the Use of a Lower Sampling Rate for Broken Rotor Bar Detection With DTFT and AR-Based Spectrum Methods
}

\author{
Bulent Ayhan, Member, IEEE, H. Joel Trussell, Fellow, IEEE, Mo-Yuen Chow, Fellow, IEEE, \\ and Myung-Hyun Song, Member, IEEE
}

\begin{abstract}
Broken rotor bars in an induction motor create asymmetries and result in abnormal amplitude of the sidebands around the fundamental supply frequency and its harmonics. Motor current signature analysis (MCSA) techniques are applied to inspect the spectrum amplitudes at the broken rotor bar specific frequencies for abnormality and to decide about broken rotor bar fault detection and diagnosis. In this paper, we have demonstrated with experimental results that the use of a lower sampling rate with a digital notch filter is feasible for MCSA in broken rotor bar detection with discrete-time Fourier transform and autoregressive-based spectrum methods. The use of the lower sampling rate does not affect the performance of the fault detection, while requiring much less computation and low cost in implementation, which would make it easier to implement in embedded systems for motor condition monitoring.
\end{abstract}

Index Terms-Broken rotor bar, fault diagnosis, induction motors, motor current signature analysis (MCSA), spectral analysis.

\section{INTRODUCTION}

I NDUCTION motors have dominated in the field of electromechanical energy conversion by having $80 \%$ of the motors in use [1]. The applications of induction motors are widespread. Some are key elements in assuring the continuity of the process and production chains of many industries. The list of the industries and applications that they take place in is rather long. A majority are used in electric utility industries, mining industries, petrochemical industries, and domestic appliance industries. Induction motors are often used in critical applications such as nuclear plants, aerospace, and military applications, where the reliability must be at high standards.

The failure of induction motors can result in a total loss of the machine itself, in addition to a likely costly downtime of the whole plant. More important, these failures may even result in the loss of lives, which cannot be tolerated. Thus, health monitoring techniques to prevent induction motor failures are

Manuscript received April 7, 2005; revised September 25, 2007.

B. Ayhan, H. J. Trussell, and M.-Y. Chow are with the Advanced Diagnosis Automation and Control Laboratory, Department of Electrical and Computer Engineering, North Carolina State University, Raleigh NC 27695 USA (e-mail: bayhan@unity.ncsu.edu; hjt@eos.ncsu.edu; chow@eos.ncsu.edu).

M.-H. Song is with the Department of Electrical Control Engineering, School of Information and Communication Engineering, Sunchon National University, Cheonnam 540-742 Korea (e-mail: mhsong@ sunchon.ac.kr).

Color versions of one or more of the figures in this paper are available online at http://ieeexplore.ieee.org.

Digital Object Identifier 10.1109/TIE.2007.896522 of great concern in industry and are gaining increasing attention [2]-[7].

Induction motors often operate in hostile environments such as corrosive and dusty places. They are also exposed to a variety of undesirable conditions and situations such as misoperations. These unwanted conditions can cause the induction motor to go into a failure period, which may result in an unserviceable condition of the motor, if not detected at its early stages of the failure period. The early detection of the incipient motor fault is thus of great concern. Rotor failures are among these failures, and they now account for the $5 \%-10 \%$ of total induction motor failures [8]. Since 1980, the broken rotor bar fault detection problem has created substantial interest among researchers [9]. Several monitoring techniques have been developed, most of which are based on vibration, thermal, and motor current signature analysis (MCSA) monitoring [11]. MCSA techniques are gaining more attention because of their easiness to use since they do not require access to the motor [12]. In recent years, several advanced signal processing techniques have been applied for MCSA. Some of these techniques are high-resolution spectral analysis, higher order statistics, and wavelet analysis [1], [10], [12], [13].

In general, MCSA techniques include parametric, nonparametric, and high-resolution spectrum analysis methods. In the parametric methods, autoregressive (AR) models have been fitted with time series of the signal, and model parameters have been used to compute the frequency spectrum. Nonparametric methods, on the other hand, are based on Fourier transform and search for periodicities of the signal. High-resolution spectrum methods correspond to an eigenvalue analysis of the autocorrelation matrix of the motor current time series signal.

One of the classical and widely used nonparametric spectrum methods as a MCSA technique is the well-known fast Fourier transform (FFT) [1]. The FFT is an algorithm to compute the discrete Fourier transform (DFT) of a discrete-time series function with minimum computational effort. FFT yields computationally efficient results, which makes it a powerful and conceptually simple MCSA technique. Power spectral density (PSD) analysis of motor current is another widely used MCSA technique [1]. There are several approaches to calculate PSD. The periodogram method, which is known as the classical way to estimate PSD, is one of the nonparametric spectrum methods [24]. Welch's periodogram is another nonparametric 
spectrum method to calculate the PSD estimate [24]. This method differs from the classical periodogram by splitting the data into overlapping segments. It then calculates the periodogram of each windowed segment and takes the average of the periodograms to find the final PSD estimate. The eigenvalue-based techniques, such as the multiple signal classification (MUSIC), are reported to deal with resolution problems, but, on the other hand, are computationally intensive [12]. The parametric spectrum methods are used for sensorless speed estimation of induction machines [14], and there are only a few reported applications of them in the condition monitoring area [15]. Burg, Yule AR, covariance, and modified covariance are well-known parametric spectrum methods. Among these methods, Yule AR provides a stable model, and its autocorrelation matrix is guaranteed to be nonsingular [23].

The spectral estimation techniques form the core of the MCSA techniques. These techniques are extensively elaborated in the signal processing media considering their pros and cons. However, there are only a few published works that have recently initiated the discussion of some of the spectral estimation techniques' feature extraction performance for the condition monitoring of rotating machinery applications [12], [15]. In [12], Benbouzid et al. have investigated high-resolution spectral analysis methods for motor condition monitoring. In [15], Cupertino has presented a performance comparison of several spectral estimation techniques on their proposed diagnostic test, which is based on the analysis of the current space vector. However, there is much need to be investigated with these techniques regarding the discipline of condition monitoring of rotating machinery systems. One important aspect is related to the selection of signal processing and filtering techniques to enhance the feature extraction performance and lessen the computational cost in implementation. The contribution of this paper is to show by experimental results that a lower sampling rate with a digital notch filter is feasible with discrete-time Fourier transform (DTFT) and AR-based spectrum methods for MCSA in broken rotor bar detection.

The broken rotor bar specific frequencies, which are also called the sideband frequencies, are located around the main line frequency. The difference (in frequency) between the closest sideband and the main line frequency depends on the motor slip factor. The motor slip factor is found using the motor rotor speed, where higher slip values indicate higher motor load conditions and lower slip values correspond to lower load conditions. The difference (in frequency) between the closest sideband and the main line frequency narrows down as the motor goes to a lower load condition. Thus, the frequency resolution must be selected higher than the difference between the closest sideband and the main line frequency; otherwise, the computed spectrum amplitudes at the sideband frequencies will not be detected since the resolution would not be adequate enough to show the sidebands. In spectral analysis, in addition to the type of the windowing function and the length of the window, the sampling rate determines the frequency resolution. Thus, the selection of the sampling rate is important. In previous works regarding the spectrum analysis of the broken rotor bar fault, in [20], $2 \mathrm{kHz}$ is applied, in [15], $1.5 \mathrm{kHz}$ is used, and in [12], $1 \mathrm{kHz}$ is applied as the sampling rate. However, there is not much discussion specific to the selection of the sampling rate. The use of notch filters has also been discussed in some previous works for enhancing the capture of sideband components. In [12], an analog 50-Hz notch filter has been used to reduce the fundamental component $(50 \mathrm{~Hz})$. In [25], an analog $50 / 60-\mathrm{Hz}$ notch filter is introduced to mainly cope with resolution problems related to magnitude differences between fundamental and sideband components. Because the magnitudes of the sideband components are considerably smaller than the magnitude of the fundamental component, the dynamic range of 12-bit analogto-digital (A/D) converters is not sufficient to cope with this issue. In [25], it is demonstrated that by using an analog notch filter, 12-bit A/D converters can be used for proper capture of the sideband components. In this paper, we have applied a lower sampling rate of $200 \mathrm{~Hz}$. One of the reasons that we select $200 \mathrm{~Hz}$ is that the sidebands of interest are in the region of $0-100 \mathrm{~Hz}$; thus, higher frequency regions will not provide any information, and a sampling rate of $200 \mathrm{~Hz}$ is believed to provide a good performance without any aliasing effects. With the applied 200-Hz sampling rate and different windowing functions used with the nonparametric spectrum methods, the frequency resolution in this paper takes a value between 1 and $6 \mathrm{~Hz}$, where the difference between the closest sideband and the main line frequency is $9.30 \pm 0.77 \mathrm{~Hz}$. Another reason is that a digital notch filter, which will not cause any significant suppression at the sidebands, can be designed efficiently at a lower sampling rate of $200 \mathrm{~Hz}$ when compared with digital notch filter designs made at higher sampling rates. In addition to these reasons, from a general point of view, the use of a lower sampling rate results in much less computation and low cost in implementation. Thus, it would be easier to design embedded systems with respect to software and hardware implementation for motor condition monitoring applications.

In this paper, the induction motor current data used are collected from an actual experiment setup in a laboratory environment. The experiments have been carried out under the full-load condition of the motor. The healthy and one broken rotor bar motor current data are sampled at $10 \mathrm{kHz}$ to allow a wide range of study with the sampling rate. The detection of the faults is performed at this rate. Then, the data are decimated to decrease the original sampling rate that is applied in the experiments to a lower value of $200 \mathrm{~Hz}$ and show that the use of the lower sampling rate does not affect the performance of the fault detection. Two nonparametric spectrum methods (i.e., DTFT and Welch's periodogram) and the Yule AR parametric method have been applied with the higher and lower sampling rates. Throughout the spectrum computation, only the spectrum amplitudes at the lower and upper sideband broken rotor bar fault specific frequencies are computed, rather than computing the overall spectrum. In this way, exact spectrum amplitudes are obtained, which improves the healthy-faulty discrimination performance and considerably decreases the computational cost. The results indicate that the sidebands can be clearly seen with the nonparametric-based methods, whereas the sidebands cannot be detected with the Yule AR method. Thus, a secondorder digital notch filter is designed to suppress the main line frequency and isolate the broken rotor bar specific sideband frequencies for the Yule AR method. This allows 
the identification of the characteristic sidebands. The spectrum amplitudes of the healthy and one broken rotor bar motor data resulting from each technique are evaluated using a statistical measure based on a hypothesis test with respect to determining the feature extraction performance. Experimental results affirm that a lower sampling rate with a notch filter can be used with DTFT and AR-based spectrum methods for broken rotor bar detection, and a significant discrimination is obtained between the healthy and faulty data sets.

This paper is organized as follows: Section II discusses the frequencies of interest to detect the broken rotor bar fault. Section III describes the fundamental properties of the three MCSA techniques. Section IV presents the experiment setup and motor data specifications. Section V introduces the decimation and digital notch filter design process. The experimental results and statistical analysis are also described in Section V. Finally, Section VI concludes the findings of this paper.

\section{Motor Current Spectral Components FOR THE BROKEN ROTOR BAR}

Kliman [16], Thomson and Stewart [17], Filipetti [18], and Elkasabgy et al. [19] used MCSA methods to detect the broken rotor bar faults by investigating the sideband components around the supplied current fundamental frequency $f_{o}$ (i.e., the line frequency). Thus

$$
f_{b}=(1 \pm 2 s) f_{o}
$$

where $f_{b}$ are the sideband frequencies associated with the broken rotor bar, and $s$ is the per-unit motor slip. The slip $s$ is defined as the relative mechanical speed of the motor $n_{m}$ with respect to the motor synchronous speed $n_{s}$, i.e.,

$$
s=\frac{n_{s}-n_{m}}{n_{s}} .
$$

The motor synchronous speed $n_{s}$ is related to the line frequency $f_{o}$, as follows:

$$
n_{s}=\frac{120 f_{o}}{P}
$$

where $P$ is the number of poles of the motor, and the constant " 120 " is used to express the motor synchronous speed $n_{s}$ in revolutions per minute $(\mathrm{r} / \mathrm{min})$ unit.

The broken rotor bars also give rise to a sequence of other sidebands, which is given by [18]

$$
f_{b}=(1 \pm 2 k s) f_{o}, \quad \text { where } f_{b}>0
$$

and is conceptually depicted in Fig. 1.

Fig. 1 shows the frequency components specific to a broken rotor bar fault, which is given in (4) for $k=1$ and 2. These frequencies are located around the fundamental line frequency and called lower sideband and upper sideband components, as indicated in Fig. 1.

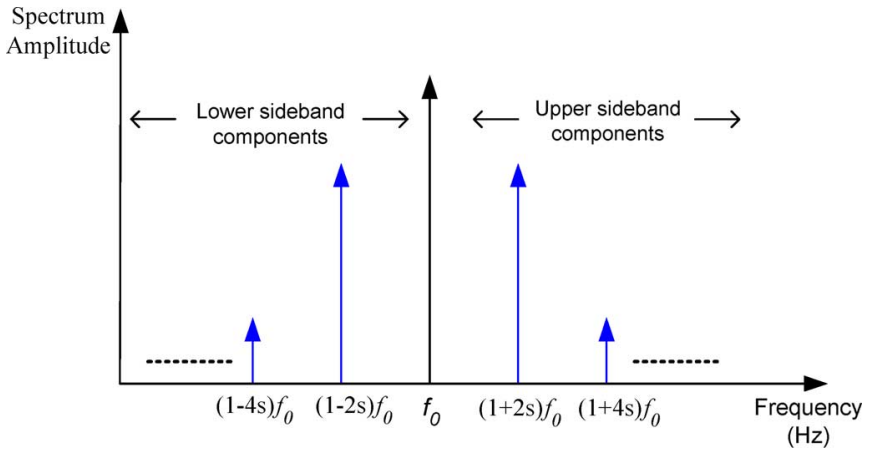

Fig. 1. Sideband frequencies around the fundamental line frequency.

\section{MCSA TECHNIQUES FOR BROKEN ROTOR BAR FAult Detection}

MCSA techniques, in general, include nonparametric, parametric, and high-resolution spectrum analysis methods. In this section, the general principles of the three investigated MCSA techniques are briefly discussed. Two of the techniques are among the nonparametric spectrum methods, i.e., DTFT and Welch's periodogram. The third technique is a parametric spectrum-based method, i.e., Yule AR.

\section{A. DTFT}

To review the basics of the DTFT, consider a sequence of $N$ equispaced samples of a finite discrete-time series signal $x[n]$, which is defined for $0 \leq n \leq N-1$. The DTFT of $x[n]$ is a representation of this sequence in terms of a complex exponential sequence $\left\{e^{-j \omega n}\right\}$, where $\omega$ is the real frequency variable $(0 \leq \omega \leq 2 \pi)$. The DTFT of $x[n]$ is depicted as $X\left(e^{j \omega}\right) \cdot X\left(e^{j \omega}\right)$ is defined as

$$
X\left(e^{j \omega}\right)=\sum_{n=0}^{N-1} x[n] w[n] e^{-j \omega n}
$$

where $w[n]$ is the window function. In this paper, $\omega$ needs to be evaluated only at two frequencies, i.e., $(1 \pm 2 s) f_{o}$; thus, the entire DFT need not to be computed. In the fault analysis with respect to the DTFT method, $\left|X\left(e^{j \omega}\right)\right|$ is used as the feature.

The selection of $w[n]$ is important and affects the resolution. The resolution of the nonparametric-based methods such as DTFT and Welch's periodogram depends on the sampling rate Fs and the window length $N_{w}$, i.e.,

$$
\Delta f=\beta \frac{\mathrm{Fs}}{N_{w}}
$$

where $\Delta f$ is the resolution, and $\beta$ depends on the applied window function $w[n]$. For the windows used in this paper, $1 \leq \beta \leq 3$.

\section{B. Welch's Periodogram Method}

In Welch's periodogram method, the data sequence $x[n]$, $\{x[0], x[1], \ldots, x[N-1]\}$, is first partitioned into $Z$ segments. The length of each segment consists of $L$ samples, and these segments can be overlapping on each other with $(L-S)$ 
overlapping samples, where $S$ is the number of points to shift between segments. Thus

Segment $1: \quad x[0], x[1], \ldots, x[L-1]$

Segment $2: \quad x[S], x[S+1], \ldots, x[L+S-1]$

Segment $Z: \quad x[N-L], x[N-L+1], \ldots, x[N-1]$.

The weighted $z$ th segment will consist of the following samples:

$$
x^{z}[n]=w[n] x[n+z S], \quad \text { for } 0 \leq n \leq L-1 ; \quad 0 \leq z \leq Z-1 .
$$

The window function $w[n]$ is applied to the data at each segment before the computation of the segment periodogram.

The sample spectrum of the weighted $z$ th segment is depicted for the real frequency value $\omega$, as follows:

$$
P_{x x}^{z}\left(e^{j \omega}\right)=\frac{1}{U L} X^{z}\left(e^{j \omega}\right)\left[X^{z}\left(e^{j \omega}\right)\right]^{*}=\frac{1}{U L}\left|X^{z}\left(e^{j \omega}\right)\right|^{2}
$$

where $U$ is the discrete-time window energy, i.e.,

$$
U=\sum_{n=0}^{L-1} w^{2}[n]
$$

and $X^{z}\left(e^{j \omega}\right)$ is the DTFT of the $z$ th segment, i.e.,

$$
X^{z}\left(e^{j \omega}\right)=\sum_{n=0}^{L-1} x^{(z)}[n] e^{-j \omega n} .
$$

Finally, Welch's PSD estimate $\hat{P}_{W}$ has been found by averaging the periodogram values of the $Z$ segments, i.e.,

$$
\begin{aligned}
\hat{P}_{W}\left(e^{j \omega}\right) & =\frac{1}{Z} \sum_{z=0}^{Z-1} P_{x x}^{z}\left(e^{j \omega}\right) \\
& =\frac{1}{Z} \sum_{z=0}^{Z-1} \frac{1}{U L}\left|\sum_{n=0}^{L-1} x^{(z)}[n] e^{-j \omega n}\right|^{2} .
\end{aligned}
$$

The factor $U$ is used to remove the effect of the window energy bias in the Welch's PSD estimator [22].

\section{Yule AR Method}

Yule AR is a parametric spectrum method based on the AR model. To compute the spectrum of $x[n],\{x[0], x[1]$, $\ldots, x[N-1]\}$, which is given over a finite interval $0 \leq n \leq$ $N-1$, first, $x[n]$ is modeled with an AR model. Then, the AR model parameters of $x[n]$ are estimated by using the autocorrelation estimates of $x[n]$ in the autocorrelation normal equation. Finally, the power spectrum is computed using the AR model parameters by a technique derived from the Wiener-Khintchine theorem [22].

In the following, the Yule AR spectrum method will be briefly introduced without going into further details. For further information, please see [21] and [22]. Suppose $x[n]$ is modeled with a $p$-order $\mathrm{AR}$ model, i.e., $\operatorname{AR}(p)$. The AR parameter
TABLE I

INDUCTION MOTOR CHARACTERISTICS USED IN THE EXPERIMENT

\begin{tabular}{|c|c|}
\hline Description & Value \\
\hline Power & $0.75 \mathrm{~kW}(1 \mathrm{Hp})$ \\
\hline Input Voltage & $380 \mathrm{~V}$ \\
\hline Full Load Current & $2.2 \mathrm{~A}$ \\
\hline Supply Frequency & $60 \mathrm{~Hz}$ \\
\hline Number of Poles & 4 \\
\hline Number of Rotor Slots & 44 \\
\hline Number of Stator Slots & 36 \\
\hline Full Load Torque & $0.43 \mathrm{~kg} \cdot \mathrm{m}$ \\
\hline Full Load Speed & $1690 \mathrm{rpm}$ \\
\hline
\end{tabular}

estimates $\hat{a}_{p}(m)$ and $\rho$ are computed by solving the following autocorrelation normal equation:

$$
\left[\begin{array}{cccc}
\hat{r}_{x}(0) & \hat{r}_{x}^{*}(1) & \ldots & \hat{r}_{x}^{*}(p) \\
\hat{r}_{x}(1) & \hat{r}_{x}(0) & \ldots & \hat{r}_{x}^{*}(p-1) \\
\vdots & \vdots & \vdots & \vdots \\
\hat{r}_{x}(p) & \hat{r}_{x}(p-1) & \ldots & \hat{r}_{x}(0)
\end{array}\right]\left[\begin{array}{c}
1 \\
\hat{a}_{p}(1) \\
\vdots \\
\hat{a}_{p}(p)
\end{array}\right]=-\left[\begin{array}{c}
\rho \\
0 \\
\vdots \\
0
\end{array}\right]
$$

where $1 \leq m \leq p$.

In (12), $\hat{r}_{x}(h)$ denotes the autocorrelation estimate and is mathematically expressed as follows:

$$
\hat{r}_{x}(h)=\frac{1}{N} \sum_{n=0}^{N-1-h} x(n+h) x^{*}(n)
$$

where $0 \leq h \leq p$. Note that the autocorrelation matrix in (12) is Hermitian Toeplitz and positive definite [22], and $\hat{r}_{x}^{*}(h)$ denotes the complex conjugate of $\hat{r}_{x}(h)$, and thus, $\hat{r}_{x}(-h)=\hat{r}_{x x}^{*}(h)$ is satisfied.

After solving the autocorrelation normal equation in (12), the AR model-order estimates $\hat{a}_{p}(m)$ and $\rho$ are found and put in (14) to find the Yule AR power spectrum $\hat{P}_{A R}$ at the real frequency value $\omega$, i.e.,

$$
\hat{P}_{\mathrm{AR}}\left(e^{j \omega}\right)=\frac{\rho}{\left|1+\sum_{m=1}^{p} \hat{a}_{p}(m) e^{-j \omega m}\right|^{2}} .
$$

\section{EXPERIMENT SETUP AND MOTOR DATA SPECIFICATIONS}

To investigate the feature extraction performance of the three investigated MCSA techniques for the broken rotor bar detection problem under a lower sampling rate, we performed experiments on an actual induction motor. The characteristics of the three-phase induction motor used in our experiment are listed in Table I. The motor was tested with a healthy rotor and with a faulty rotor that had one broken rotor bar. The broken rotor bar fault was induced by filling a small crack-size piece in one of the rotor bars full with anchoring cement before the die-casting process. Anchoring cement is a high-strength fastsetting gypsum cement with low conductivity. The overall data collection scheme and the actual experiment setup picture are depicted in Figs. 2 and 3, respectively.

The induction motor was fed through a three-phase ABB, ACS 501 inverter. A Tektronix TM 5003 current amplifier 


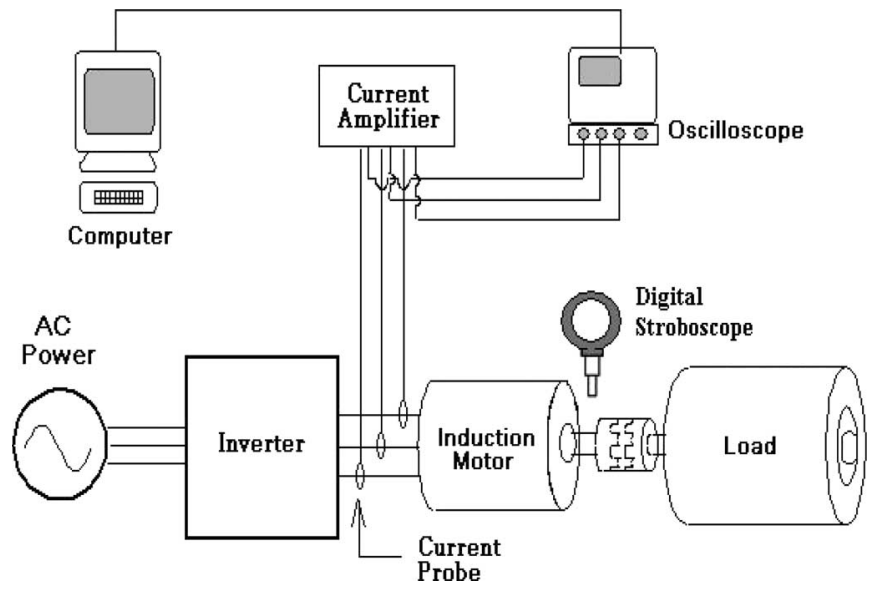

Fig. 2. Motor data collection scheme.

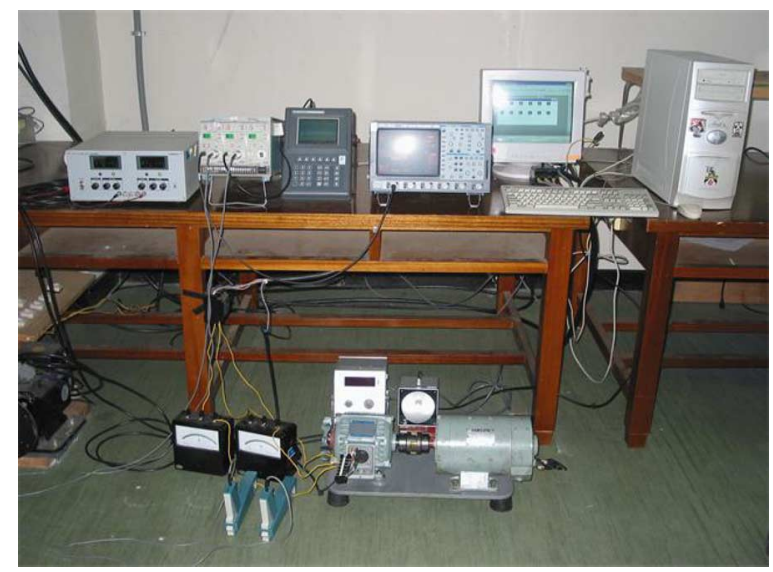

Fig. 3. Actual experiment setup to collect healthy and faulty motor data.

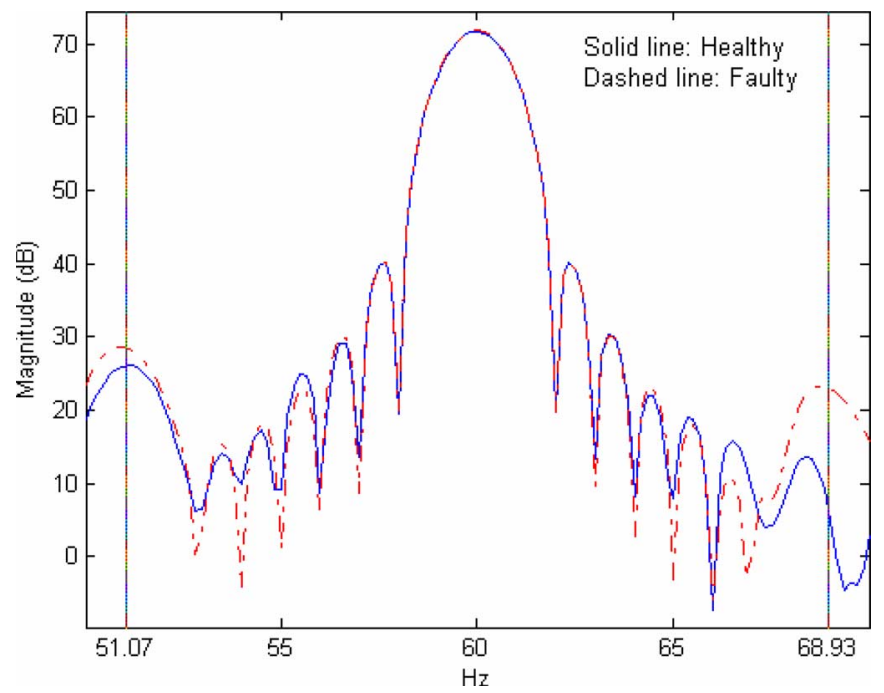

Fig. 4. DTFT of healthy and faulty motor current data with Hanning window (no filtering applied, Fs $=10 \mathrm{kHz}$ ). Vertical lines indicate the location of the fault specific sidebands.

amplifies the induction motor stator currents before being sent to the interfacing Pentium PC through the oscilloscope. The needed load condition of the induction motor was established by connecting the test motor to a dc motor, which is used as a generator and is capable of simulating any desired load

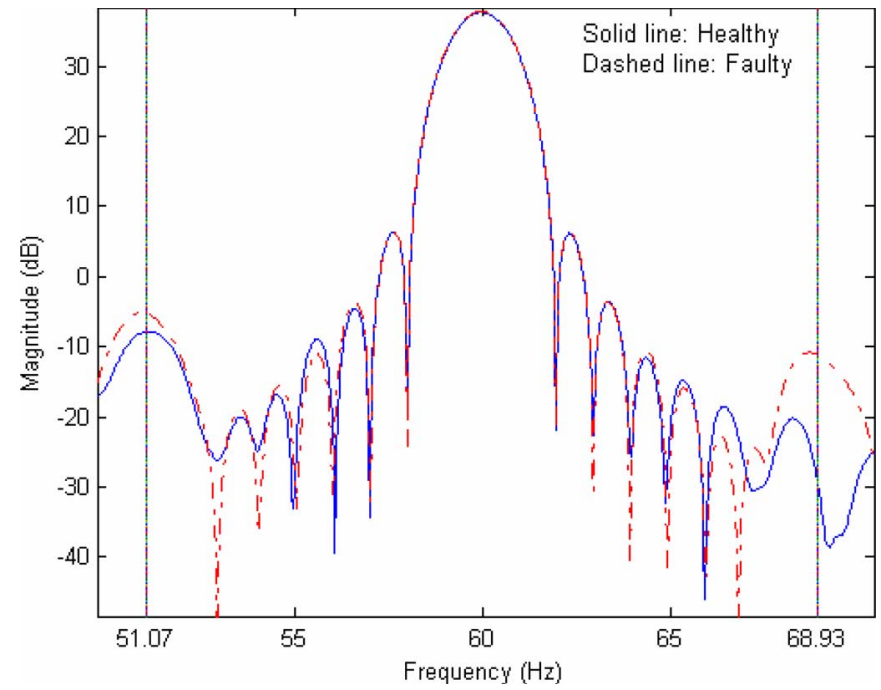

Fig. 5. DTFT of healthy and faulty motor current data with Hanning window (no filtering applied, $\mathrm{Fs}=200 \mathrm{~Hz}$ ).

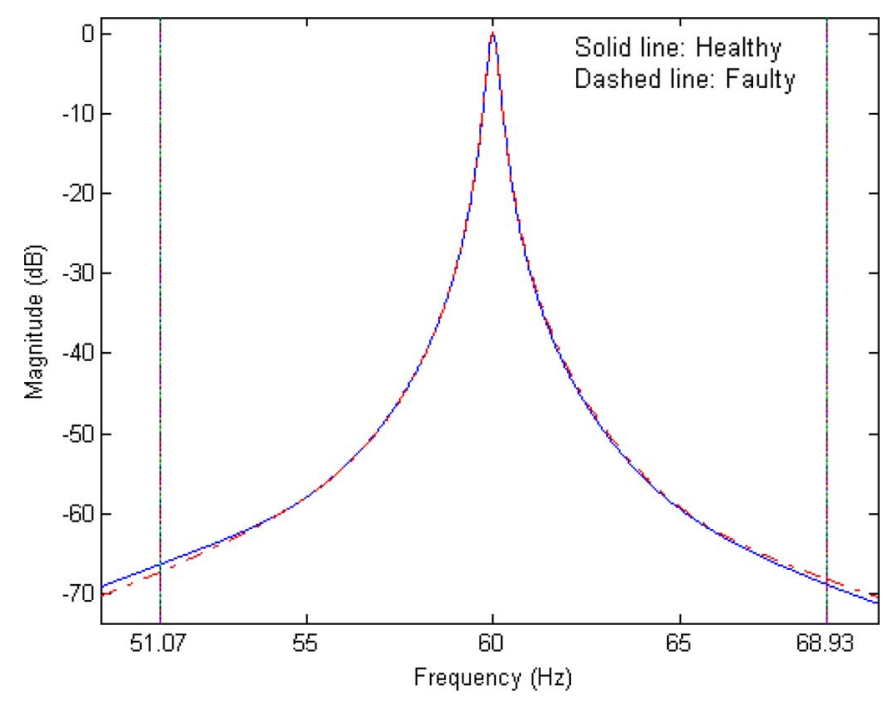

Fig. 6. Yule AR spectrum of the decimated data $(F s=200 \mathrm{~Hz}$, model order $=30$ ).

condition. The speed of the induction motor was measured by a digital stroboscope.

The experiments involved collecting three-phase stator induction motor current and speed data for the full-load condition of the motor both with one broken rotor bar fault and without any fault. The motor load condition is determined according to the motor nameplate information given in Table I. Thus, there are two different experiment cases: 1) healthy motor (no broken bar) under full load and 2) motor with one broken rotor bar under full load. For each individual case, 20 sets of motor current data were collected with a sampling rate of $10 \mathrm{kHz}$, i.e., Fs $=10 \mathrm{kHz}$. Thus, each motor current data set contains 10000 samples for a duration of $1 \mathrm{~s}$.

\section{EXPERIMENTAL RESUlTS AND ANALYSIS}

As described in Section II, broken rotor bar fault specific frequencies depend on motor's slip, which is a function of 


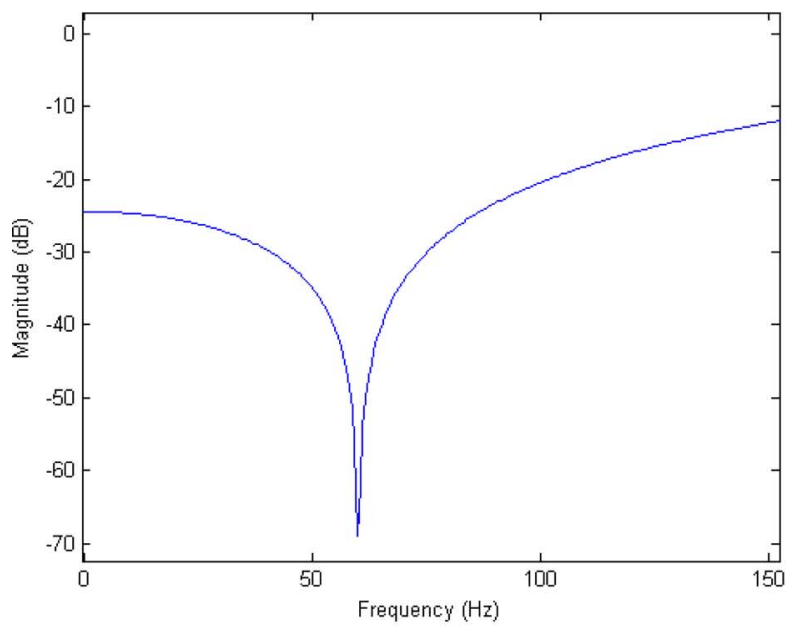

(a)

Fig. 7. Notch filter designs with Fs $=10 \mathrm{kHz}$. (a) $r_{p}=0.85$. (b) $r_{p}=0.99$.

motor's synchronous speed and motor's actual speed. In this paper, the spectrum amplitudes of the motor current (phase a) at the two frequencies specific to the broken rotor bar fault are investigated. These two frequencies are the first lower and upper sidebands, i.e., $(1-2 s) f_{o}$ and $(1+2 s) f_{o}$, respectively, which are derived from (4).

Finding the spectrum amplitudes at the actual frequency components $f_{b}$, which are specific to the broken rotor bar fault, is important to make an accurate decision about the existence of a fault. These frequency components are computed by first incorporating the actual motor speed data values into (2) to find the slip values. The computed slip values are then used in (1) to find the frequency components. According to the experimental data, the motor speed under the full-load condition varies between 1649 and $1672 \mathrm{r} / \mathrm{min}$. Thus, using (1), the lower sideband frequency location is found to vary between 49.93 and $51.47 \mathrm{~Hz}$, whereas the upper sideband frequency location varies between 68.53 and $70.07 \mathrm{~Hz}$.

Fig. 4 depicts the DTFT spectrum of healthy and one broken rotor bar motor current data at the original sampling rate of Fs $=10 \mathrm{kHz}$, with Hanning window applied. The lower and upper sidebands should be examined at 51.07 and $68.93 \mathrm{~Hz}$ according to the corresponding speed data. These frequency locations are marked with vertical lines in Fig. 4. The solid line represents the spectrum of the healthy motor data, whereas the dashed line corresponds to the spectrum of the broken rotor bar data. The motor current data are decimated with a decimation rate of 50. In this way, the sampling rate is reduced by a factor of 50, i.e., Fs $=200 \mathrm{~Hz}$. In Fig. 5, the DTFT spectra of the decimated healthy and faulty motor current data with Hanning window are depicted. From Figs. 4 and 5, it can be clearly seen that the sidebands of interest can be detected with the DTFT method both with the higher sampling rate of $\mathrm{Fs}=10 \mathrm{kHz}$ and the lower sampling rate of Fs $=200 \mathrm{~Hz}$. For the feature extraction performance analysis of the three investigated methods, the DTFT at only the two sideband frequencies $(1 \pm 2 s) f_{o}$ are computed, which are indicated by the vertical lines in Figs. 4 and 5. Fig. 6 depicts the Yule AR spectrum of the decimated healthy and faulty motor current data with a model order

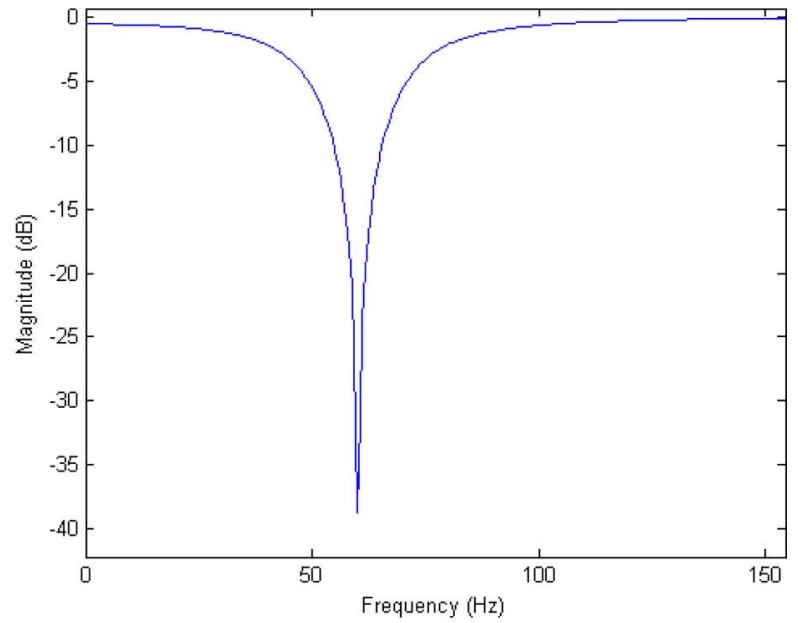

(b)

of 30. Unlike the DTFT method, the two sidebands cannot be seen since the dominance of the main line frequency does not allow the sidebands to appear with the Yule AR method. Thus, a filtering process is needed to suppress the main line frequency. In Section V-A, the filter design process is introduced, which will enable the Yule AR method to be applicable for broken rotor bar detection.

\section{A. Notch Filter Design}

The motivation behind applying a notch filter is to isolate the two sidebands of interest by suppressing the dominance of the main line frequency, such that Yule AR method can be successfully applied for broken rotor bar detection.

The transfer function of a second-order notch filter $N(z)$ can be mathematically expressed as

$$
N(z)=N_{\text {gain }} \frac{\left(z-r_{z} e^{j \omega_{c}}\right)\left(z-r_{z} e^{-j \omega_{c}}\right)}{\left(z-r_{p} e^{j \omega_{c}}\right)\left(z-r_{p} e^{-j \omega_{c}}\right)}
$$

where $\omega_{c}$ denotes the notch frequency $\left(0<\omega_{c}<2 \pi\right), r_{z}$ denotes the zero radius $\left(0 \ll r_{z} \leq 1\right), r_{p}$ denotes the pole radius $\left(0 \ll r_{p}<1\right)$, and $N_{\text {gain }}$ denotes the gain.

We have set $r_{z}$ and $N_{\text {gain }}$ to 1 and considered several different values for $r_{p}$, i.e., in the range $0.85<r_{p}<0.99$. It is observed that the $60-\mathrm{Hz}\left(f_{o}\right)$ second-order notch filter design for the higher sampling rate of $\mathrm{Fs}=10 \mathrm{kHz}$ causes high attenuations at the two sidebands. Fig. 7 depicts the magnitude responses of the notch filters for Fs $=10 \mathrm{kHz}$, with $r_{p}=0.85$ and 0.99 , respectively. From Fig. 7, it can be seen that the sidebands $(1-2 s) f_{o}$ and $(1+2 s) f_{o}$ are significantly attenuated, in addition to the attenuation of $f_{o}$. To obtain a lower attenuation at this sampling rate, the poles would have to be much closer to the unit circle. This will produce unacceptable instabilities caused by numerical roundoff. Thus, we do not further consider this case.

At the lower sampling rate of $\mathrm{Fs}=200 \mathrm{~Hz}$, the notch filter can be effectively implemented for reasonable pole radii. We have evaluated the magnitude responses of the filter designs 

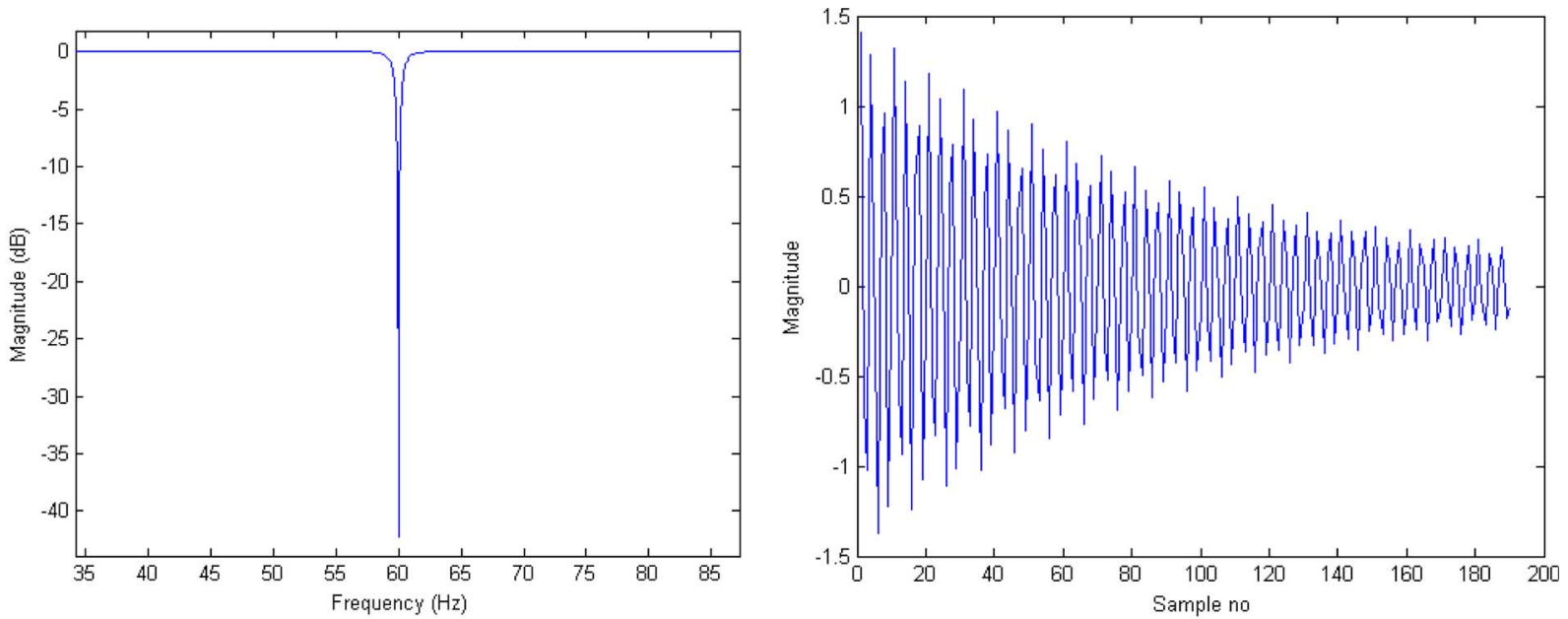

(a)
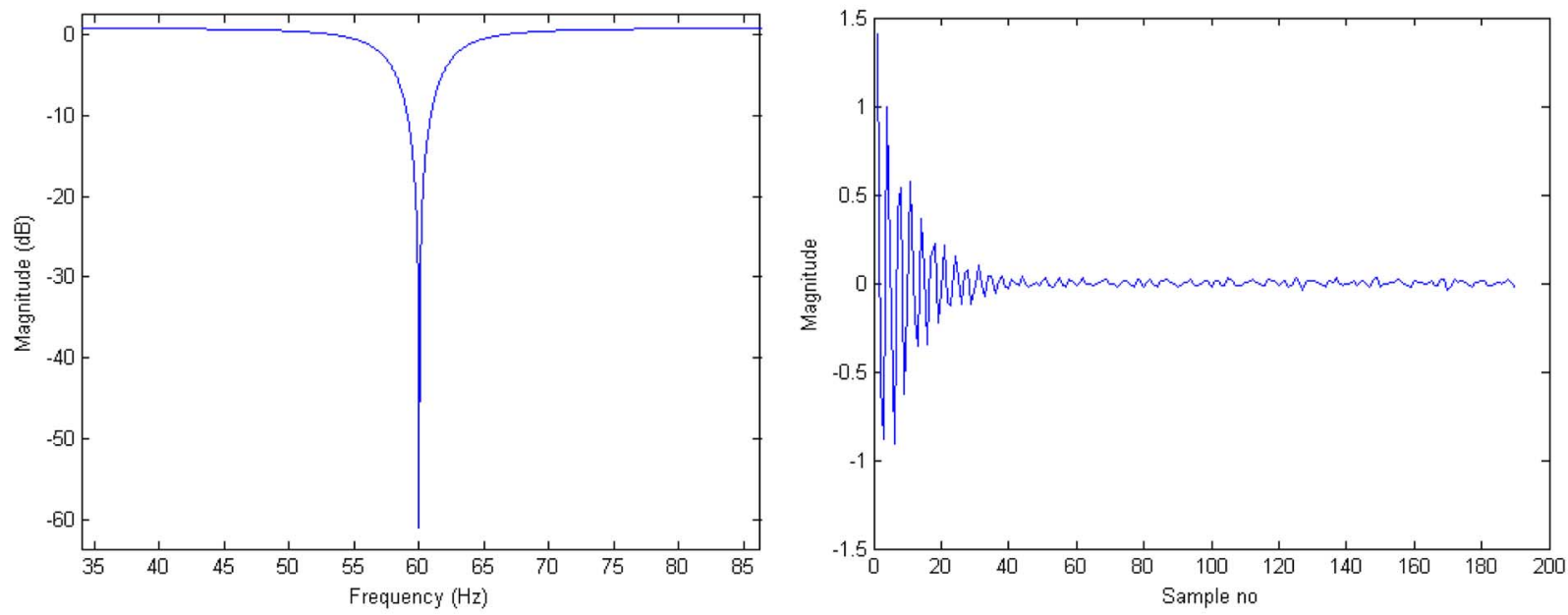

(b)
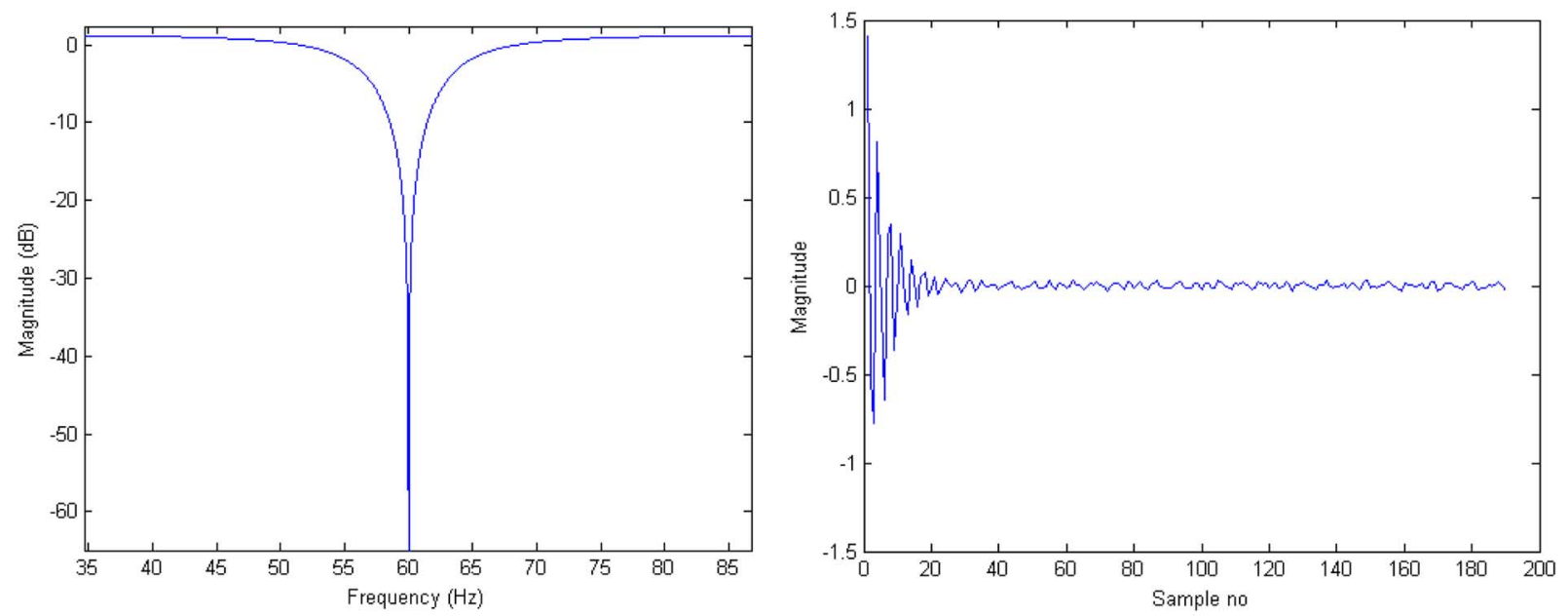

(c)

Fig. 8. Notch filter magnitude responses with different pole radii and output data after filtering. (a) $r_{p}=0.99$. (b) $r_{p}=0.91$. (c) $r_{p}=0.85$.

and considered their transient response when applied to motor current data. Fig. 8 depicts notch filter magnitude responses and their application to motor current data for $r_{p}=0.85,0.91$, and 0.99 . From the magnitude responses of the investigated notch filter designs, it is observed that as the $r_{p}$ value approaches 1, a sharper filter magnitude response is obtained. However, a notch filter with a sharp magnitude response pro- duces a long transient response in the output data. Thus, there is a tradeoff between designing a sharp notch filter and obtaining enough number of steady samples needed for motor current spectrum computation. Since steady-state responses of the notch filtered data are needed to compute the spectrum, the sharpest filter could not be used since its transient response is longer than the window. The notch filter design with $r_{p}=0.99$, 


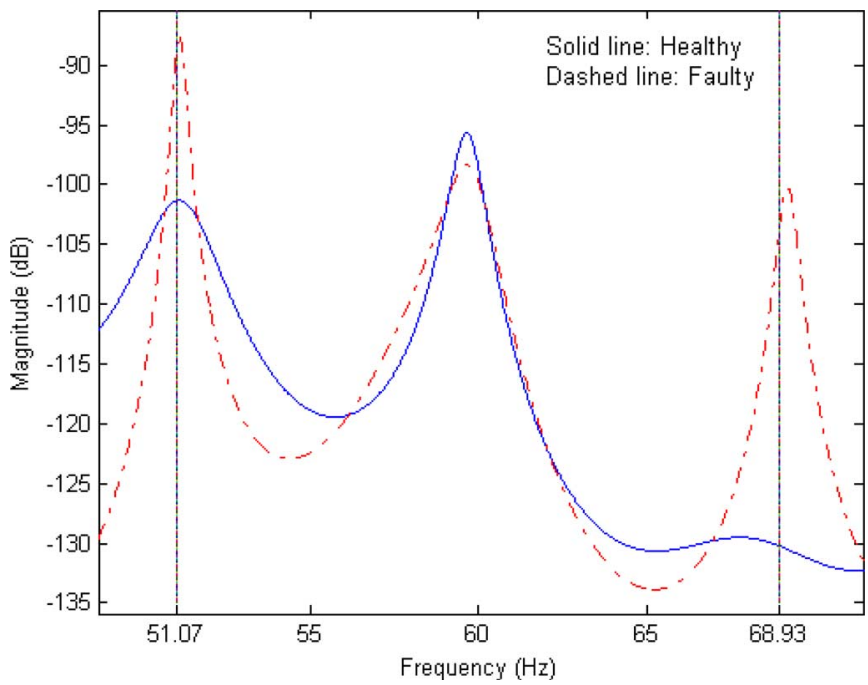

Fig. 9. Yule AR spectrum of the notch filtered data with $F s=200 \mathrm{~Hz}$.

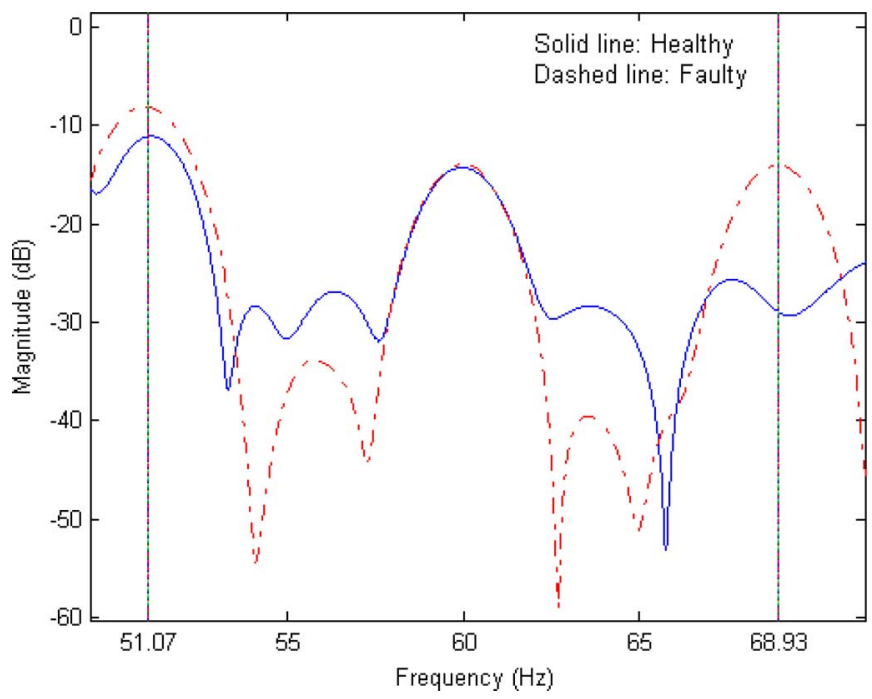

Fig. 10. DTFT of the notch filtered data with Fs $=200 \mathrm{~Hz}$.

which is depicted in Fig. 8(a), demonstrates this case. As can be seen from the magnitude responses, although the notch filter provides a sharp response, the output data consist of only transient response but no steady-state response.

The spectra in Fig. 9 correspond to the same healthy and broken rotor motor current data pairs that were used in Figs. 4-6. A model order of 30 has been applied in the Yule AR method. Before applying Yule AR, the decimated motor current data are filtered with a second-order notch filter with an $r_{p}$ value of 0.91 . Thus, Fig. 9 verifies that the lower and upper sidebands can be successfully detected after notch filtering with the Yule AR method with a lower sampling rate of $F s=200 \mathrm{~Hz}$. From Figs. 4 and 5, it is seen that the DTFT method (with Hanning window) reveals the sidebands of interest without applying filtering both with the higher and lower sampling rates. Fig. 10 illustrates that the sidebands can also be seen with the notch filtered data using DTFT (with Hanning window) under Fs $=200 \mathrm{~Hz}$.

To illustrate that the lower sampling rate with a notch filter can be successfully applied for broken rotor bar detection with the three investigated spectrum methods, we have incorpo-

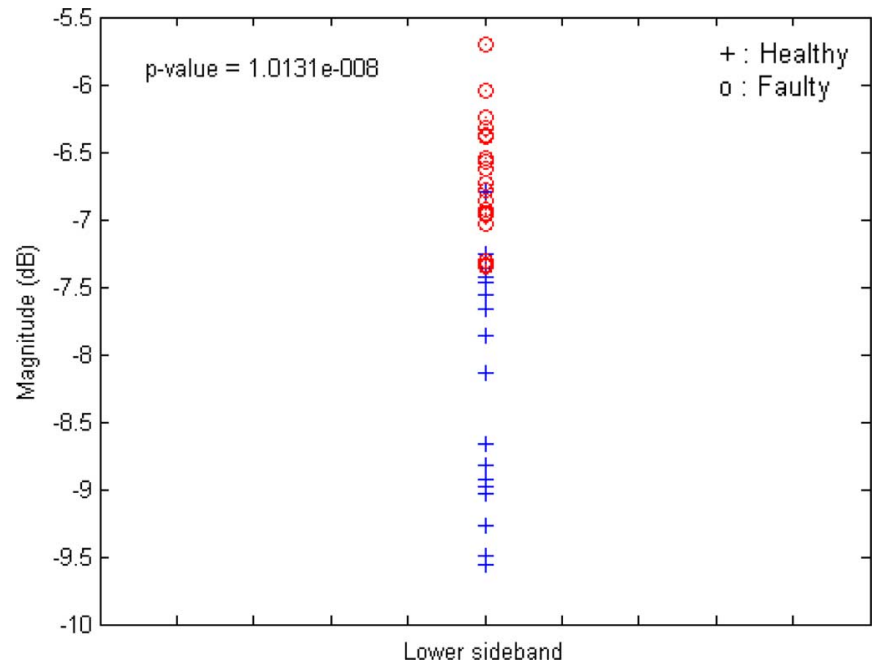

Fig. 11. DTFT amplitudes of the notch filtered healthy and faulty data sets at the lower sideband.

rated a performance measure in our analyses. The performance measure is based on a hypothesis test that statistically shows the difference among the observed spectrum estimates of the healthy and broken rotor bar data sets. The hypotheses are stated in the list that follows.

$H_{0}$ : The mean of healthy motor spectrum estimates is the same as the mean of faulty motor spectrum estimates at the inspected frequency.

$H_{1}$ : The mean of healthy motor spectrum estimates is not the same as the mean of faulty motor spectrum estimates at the inspected frequency.

We apply these hypotheses on the two specific frequencies under investigation for the three spectrum methods. We then use $t$-test $p$-value results to determine if the hypothesis test is significant with the spectrum data under investigation [23].

In general, the $t$-test allows us to assess whether the means of two groups are statistically different from each other. The $t$-test evaluates the means of the compared groups relative to the variability of their samples. In our case, the two groups under comparison are healthy and faulty spectrum estimates under the full-load condition of the motor. The numerical value that the $p$-value yields is a probability value, which gives information on whether the two groups differ from each other and at what degree. If the $p$-value is smaller than a predefined significance level, then the null hypothesis $H_{0}$ is rejected. This implies that the difference between the means of the compared groups is statistically significant. Otherwise $H_{1}$ is rejected. In other words, as the $p$-values become smaller, the discrimination between the two groups becomes more significant. A significance level value of 0.05 , which is also interpreted as a $95 \%$ confidence interval, is the most commonly used significance level in statistics for classification problems [23].

To give a visual insight to the reader about the relation between the $p$-value and the discrimination rate, the DTFT amplitudes of the notch filtered healthy and faulty data sets with $\mathrm{Fs}=200 \mathrm{~Hz}$ for the lower and upper sidebands are depicted in Figs. 11 and 12, respectively. In Figs. 11 and 12, the applied second-order notch filter has an $r_{p}$ value of 0.91 , and the DTFT amplitudes are computed with a Hamming window that has 


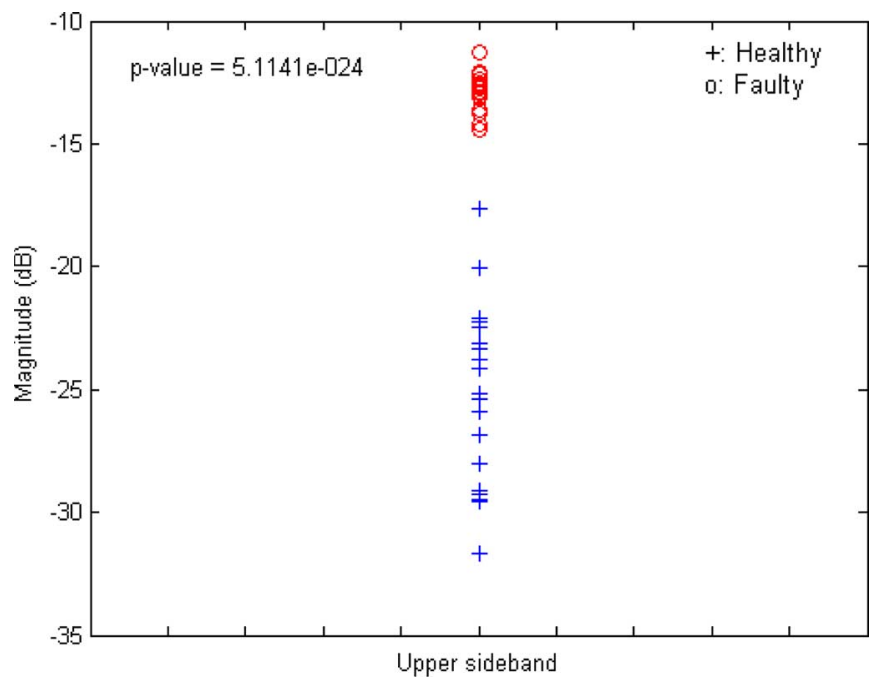

Fig. 12. DTFT amplitudes of the notch filtered healthy and faulty data sets at the upper sideband.

a window size of 150. From Figs. 11 and 12, it can be seen that as the $p$-values become smaller, the discrimination of the two groups becomes more significant (a $p$-value of $5.11 \mathrm{e}-24$ has no overlapping samples, whereas a $p$-value of $1.01 \mathrm{e}-08$ has a few).

In the remaining parts of this section, we will show the feature extraction performance of the three investigated methods. For DTFT and Welch's periodogram, we will consider three cases: 1) higher sampling rate with no filtering; 2) lower sampling rate (after decimation) with no filtering; and 3) lower sampling rate with notch filter. For the Yule AR method, we will only consider the lower sampling rate with no filtering and lower sampling rate with notch filter cases. This is because with the Yule AR method, the sidebands of interest cannot be seen without filtering. Thus, the case of higher sampling rate with no filtering is of no use.

\section{B. Feature Extraction Performance of DTFT}

In this paper, we have considered several windowing techniques when applying the DTFT and Welch's periodogram methods since the type of the windowing technique is a significant factor that affects the feature extraction performance. We have applied eight different windows with the DTFT method: 1) rectangular; 2) triangular; 3) Hamming; 4) Gaussian; 5) Hanning; 6) Parzen; 7) Nuttall; and 8) Chebyschev (100 dB). Figs. 13 and 14 depict four of these windows and their magnitude responses, respectively. In Fig. 13, the $x$-axis represents the width of the discrete-time window function in samples. In this particular demonstration, the window functions consist of 64 samples. In Fig. 14, the magnitude responses of the four windows are depicted. The $x$-axis in Fig. 14 corresponds to the frequency and is scaled with respect to the sampling frequency (digital frequency), which is common in digital signal processing. Fig. 14 provides an illustration about how a signal, whose frequency is actually located at zero, "leaks" into the neighboring frequency bins.

Tables II and III depict the $p$-values for the DTFT method with eight windows for the three cases at the lower and upper

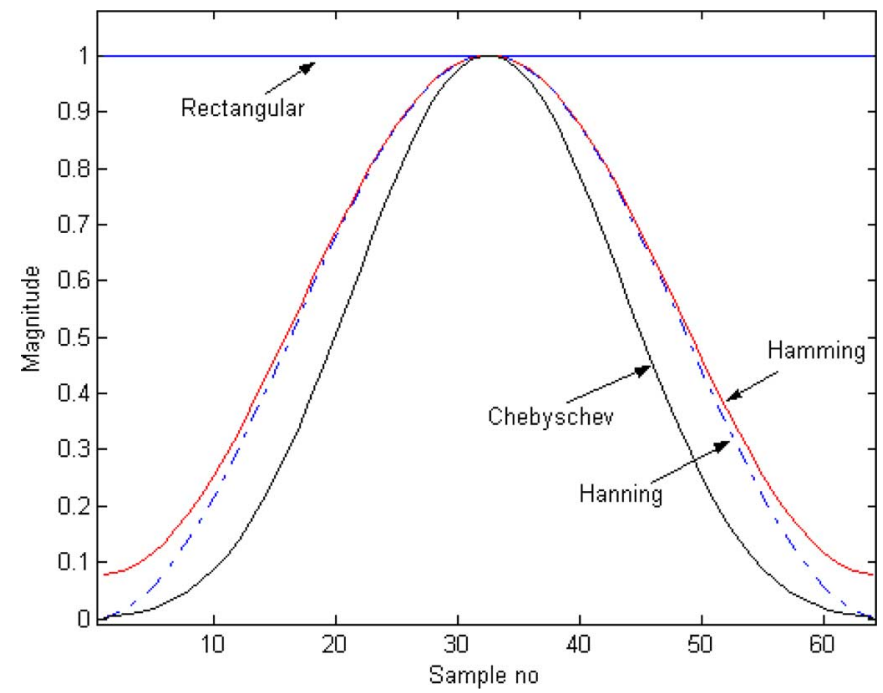

Fig. 13. Four of the windows used in the DTFT method.

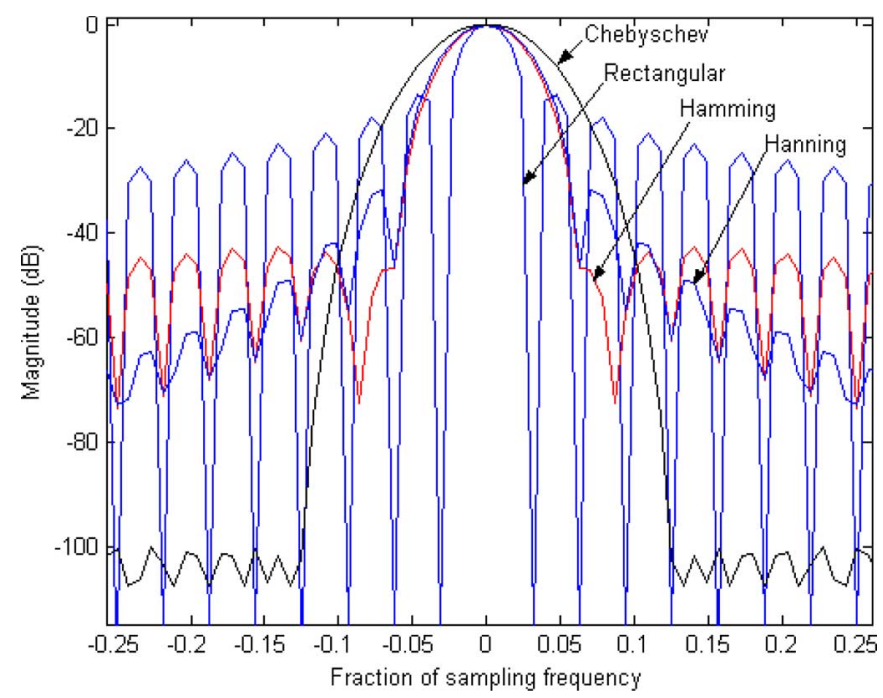

Fig. 14. Magnitude responses of the four windows.

sidebands, respectively. According to Tables II and III, for the higher sampling rate with no filtering and lower sampling rate with no filtering cases, the Hanning, Parzen, Nuttall, and Chebyschev $(100 \mathrm{~dB})$ windows are observed to provide high healthy-faulty discrimination performance (because of low $p$-values), whereas the rectangular, triangular, Gaussian, and Hamming windows are not satisfactory. This is caused by the leakage of the main line frequency. The rectangular, triangular, Hamming, and Gaussian windows barely suppress the main line frequency and are not adequate for suppression of $50 \mathrm{~dB}$ and above. On the other hand, Hanning, Parzen, Nuttall, and Chebyschev (100 dB) provide adequate suppression. Regarding the lower sampling rate with notch filter case results, all windows are observed to provide satisfactory results by providing low $p$-values. In addition, the $p$-values in Table III were lower than the $p$-values in Table II, indicating that the upper sideband $(1+2 s) f_{o}$ has more discriminative information than the lower sideband $(1-2 s) f_{o}$. 
TABLE II

$p$-VAlues For DTFT With DifFERENT Windows FOR THE LOWER Sideband FOR THE THREe CASES

\begin{tabular}{|c|c|c|c|}
\hline Window type & $\begin{array}{c}(1-2 s) f_{o} \mathbf{p} \text {-value } \\
\text { no filtering (window } \\
\text { size }=\mathbf{1 0 , 0 0 0}, \mathbf{F s}=\mathbf{1 0 k H z})\end{array}$ & $\begin{array}{c}(1-2 s) f_{o} \mathbf{p} \text {-value } \\
\text { no filtering (window size } \\
\mathbf{2 0 0}, \mathbf{F s}=\mathbf{2 0 0} \mathbf{H z})\end{array}$ & $\begin{array}{c}(1-2 s) f_{o} \mathbf{p} \text {-value } \\
\text { notch filtering (window } \\
\left.\text { size=150, } r_{p}=\mathbf{0 . 9 1}, \mathbf{F s}=\mathbf{2 0 0} \mathbf{H z}\right)\end{array}$ \\
\hline Rectangular & 0.60 & 0.62 & $1.08 \mathrm{e}-07$ \\
\hline Triangular & 0.52 & 0.68 & $1.32 \mathrm{e}-08$ \\
\hline Hamming & 0.94 & 0.59 & $1.01 \mathrm{e}-08$ \\
\hline Gaussian & 0.43 & 0.23 & $2.14 \mathrm{e}-08$ \\
\hline Hanning & $3.72 \mathrm{e}-08$ & $3.61 \mathrm{e}-08$ & $2.22 \mathrm{e}-08$ \\
\hline Parzen & $4.75 \mathrm{e}-08$ & $4.82 \mathrm{e}-08$ & $3.10 \mathrm{e}-07$ \\
\hline Nuttall & $2.12 \mathrm{e}-08$ & $1.95 \mathrm{e}-08$ & $4.72 \mathrm{e}-07$ \\
\hline Chebyschev $\mathbf{( 1 0 0} \mathbf{d B})$ & $1.99 \mathrm{e}-08$ & $1.79 \mathrm{e}-08$ & $3.86 \mathrm{e}-07$ \\
\hline
\end{tabular}

TABLE III

$p$-VAlues For DTFT With Different Windows For THE UPPER Sideband For the Three CaSes

\begin{tabular}{|c|c|c|c|}
\hline Window type & $\begin{array}{c}(1+2 s) f_{o} \mathbf{p}-\mathbf{v a l u e} \\
\text { no filtering (window } \\
\text { size }=\mathbf{1 0 , 0 0 0}, \mathbf{F s}=\mathbf{1 0 k H z})\end{array}$ & $\begin{array}{c}(1+2 s) f_{o} \mathbf{p} \text {-value } \\
\text { no filtering (window size } \\
\mathbf{2 0 0}, \mathbf{F s}=\mathbf{2 0 0} \mathbf{H z})\end{array}$ & $\begin{array}{c}(1+2 s) f_{o} \mathbf{p} \text {-value } \\
\text { notch filtering (window } \\
\left.\text { size= } \mathbf{1 5 0}, r_{p}=\mathbf{0 . 9 1}, \mathbf{F s}=\mathbf{2 0 0} \mathbf{H z}\right)\end{array}$ \\
\hline Rectangular & 0.94 & 0.85 & $7.82 \mathrm{e}-18$ \\
\hline Triangular & 0.36 & 0.56 & $7.28 \mathrm{e}-24$ \\
\hline Hamming & 0.01 & 0.04 & $5.11 \mathrm{e}-24$ \\
\hline Gaussian & $7.04 \mathrm{e}-05$ & $4.01 \mathrm{e}-04$ & $9.88 \mathrm{e}-24$ \\
\hline Hanning & $2.15 \mathrm{e}-22$ & $6.99 \mathrm{e}-23$ & $1.28 \mathrm{e}-23$ \\
\hline Parzen & $3.01 \mathrm{e}-23$ & $2.66 \mathrm{e}-23$ & $5.71 \mathrm{e}-22$ \\
\hline Nuttall & $1.48 \mathrm{e}-23$ & $1.28 \mathrm{e}-23$ & $1.04 \mathrm{e}-21$ \\
\hline Chebyschev $\mathbf{1 0 0} \mathbf{d B})$ & $1.28 \mathrm{e}-23$ & $1.07 \mathrm{e}-23$ & $7.52 \mathrm{e}-22$ \\
\hline
\end{tabular}

TABLE IV

$p$-Values for Welch's Periodogram Method Under Different Window Sizes and Overlapping SAMPLES FOR THE LOWER Sideband With No FILTERING AND Fs $=10 \mathrm{kHz}$

\begin{tabular}{|c|c|c|c|c|c|c|}
\hline \multirow{2}{*}{$\begin{array}{l}\text { Window } \\
\text { size }\end{array}$} & \multirow{2}{*}{$\begin{array}{l}\text { Overlapping } \\
\text { Samples }\end{array}$} & \multirow{2}{*}{$\begin{array}{l}\text { Number of } \\
\text { Windows }\end{array}$} & \multicolumn{4}{|c|}{$(1-2 s) f_{o}$ p-value with no filtering, $\mathbf{F s}=\mathbf{1 0} \mathbf{~ k H z}$} \\
\hline & & & Rectangular & Hamming & Hanning & $\begin{array}{c}\text { Chebyschev } \\
(100 \mathrm{~dB})\end{array}$ \\
\hline 10,000 & 0 & 1 & 0.26 & 0.89 & $3.10 \mathrm{e}-08$ & $1.31 \mathrm{e}-08$ \\
\hline 9,500 & 9,000 & 2 & 0.62 & $2.48 \mathrm{e}-04$ & $3.22 \mathrm{e}-09$ & $1.52 \mathrm{e}-08$ \\
\hline 9,000 & 8,500 & 3 & 0.96 & 0.01 & $1.06 \mathrm{e}-08$ & $1.79 \mathrm{e}-08$ \\
\hline 8,000 & 7,500 & 5 & 0.41 & $5.06 \mathrm{e}-04$ & $1.08 \mathrm{e}-08$ & $1.83 \mathrm{e}-08$ \\
\hline 7,000 & 6,500 & 7 & 0.48 & $4.57 \mathrm{e}-04$ & $7.61 \mathrm{e}-09$ & $1.22 \mathrm{e}-08$ \\
\hline 6,000 & 5,500 & 9 & 0.65 & $0.51 \mathrm{e}-02$ & $3.32 \mathrm{e}-09$ & $6.12 \mathrm{e}-09$ \\
\hline 5,000 & 4,500 & 11 & 0.04 & 0.19 & $5.95 \mathrm{e}-07$ & $3.39 \mathrm{e}-09$ \\
\hline 5,000 & 4,000 & 6 & 0.04 & 0.91 & 0.01 & $2.81 \mathrm{e}-09$ \\
\hline 5,000 & 2,500 & 3 & 0.03 & 0.74 & $6.46 \mathrm{e}-04$ & $6.38 \mathrm{e}-09$ \\
\hline 4,000 & 2,000 & 4 & $0.40 \mathrm{e}-02$ & 0.72 & 0.93 & $4.49 \mathrm{e}-08$ \\
\hline
\end{tabular}

TABLE V

$p$-Values For Welch's Periodogram Method Under DifFerent Window Sizes and Overlapping SAMPLES FOR THE LOWER Sideband With No FILTERING AND Fs $=200 \mathrm{~Hz}$

\begin{tabular}{|c|c|c|c|c|c|c|}
\hline \multirow{2}{*}{$\begin{array}{l}\text { Window } \\
\text { size }\end{array}$} & \multirow{2}{*}{$\begin{array}{c}\text { Overlapping } \\
\text { Samples }\end{array}$} & \multirow{2}{*}{$\begin{array}{l}\text { Number of } \\
\text { Windows }\end{array}$} & \multicolumn{4}{|c|}{$(1-2 s) f_{o}$ p-value with no filtering, $\mathbf{F s}=\mathbf{2 0 0} \mathbf{~ H z}$} \\
\hline & & & Rectangular & Hamming & Hanning & $\begin{array}{c}\text { Chebyschev } \\
(100 \mathrm{~dB})\end{array}$ \\
\hline 200 & 0 & 1 & 0.30 & 0.68 & $3.10 \mathrm{e}-08$ & $1.19 \mathrm{e}-08$ \\
\hline 180 & 160 & 2 & 0.69 & 0.62 & $1.33 \mathrm{e}-07$ & $1.50 \mathrm{e}-08$ \\
\hline 160 & 140 & 3 & 0.75 & 0.47 & $8.46 \mathrm{e}-07$ & $1.33 \mathrm{e}-08$ \\
\hline 140 & 120 & 4 & 0.80 & 0.50 & $9.75 \mathrm{e}-06$ & $8.15 \mathrm{e}-09$ \\
\hline 120 & 100 & 5 & 0.45 & 0.83 & $1.70 \mathrm{e}-004$ & $4.20 \mathrm{e}-09$ \\
\hline 100 & 80 & 6 & 0.03 & 0.58 & $0.79 \mathrm{e}-02$ & $2.76 \mathrm{e}-09$ \\
\hline 100 & 50 & 3 & 0.03 & 0.73 & $0.11 \mathrm{e}-02$ & $6.35 \mathrm{e}-09$ \\
\hline
\end{tabular}

\section{Feature Extraction Performance of Welch's Periodogram}

The rectangular, Hamming, Hanning, and Chebyschev windows are applied in Welch's periodogram. Tables IV-VI depict the $p$-values for the Welch's periodogram method at the lower sideband for the three cases. In Tables IV-VI, it is seen that for some combinations of overlapping samples and window sizes, the Welch's periodogram method has generated lower $p$-values for the lower sideband when compared with DTFT, e.g., for the 
TABLE VI

$p$-Values For Welch's Periodogram Method Under DifFerent Window Sizes AND OVERLAPPing SAMPLES FOR THE LOWER SIDEBAND With NOTCH FILTERING AND Fs $=200 \mathrm{~Hz}$

\begin{tabular}{|c|c|c|c|c|c|c|}
\hline \multirow{2}{*}{$\begin{array}{l}\text { Window } \\
\text { size }\end{array}$} & \multirow{2}{*}{$\begin{array}{c}\text { Overlapping } \\
\text { Samples }\end{array}$} & \multirow{2}{*}{$\begin{array}{l}\text { Number of } \\
\text { Windows }\end{array}$} & \multicolumn{4}{|c|}{$(1-2 s) f_{o} \mathbf{p}$-value notch filtering $\left(r_{p}=0.91\right)$ and $\mathbf{F s}=200 \mathbf{H z}$} \\
\hline & & & Rectangular & Hamming & Hanning & $\begin{array}{c}\text { Chebyschev } \\
(100 \mathrm{~dB})\end{array}$ \\
\hline 150 & 0 & 1 & $9.51 \mathrm{e}-08$ & $7.11 \mathrm{e}-09$ & $1.54 \mathrm{e}-08$ & $2.42 \mathrm{e}-07$ \\
\hline 140 & 130 & 2 & $2.00 \mathrm{e}-09$ & $1.39 \mathrm{e}-08$ & $2.33 \mathrm{e}-08$ & $3.82 \mathrm{e}-07$ \\
\hline 130 & 120 & 3 & $1.73 \mathrm{e}-09$ & $2.03 \mathrm{e}-08$ & $3.62 \mathrm{e}-08$ & $4.52 \mathrm{e}-07$ \\
\hline 120 & 110 & 4 & $1.16 \mathrm{e}-09$ & $2.69 \mathrm{e}-08$ & $4.99 \mathrm{e}-08$ & $3.95 \mathrm{e}-07$ \\
\hline 110 & 100 & 5 & $2.03 \mathrm{e}-09$ & $3.12 \mathrm{e}-08$ & $5.28 \mathrm{e}-08$ & $2.46 \mathrm{e}-07$ \\
\hline 100 & 90 & 6 & $1.99 \mathrm{e}-09$ & $2.58 \mathrm{e}-08$ & $4.10 \mathrm{e}-08$ & $1.12 \mathrm{e}-07$ \\
\hline 100 & 50 & 2 & $4.98 \mathrm{e}-07$ & $1.53 \mathrm{e}-09$ & $2.39 \mathrm{e}-09$ & $2.30 \mathrm{e}-09$ \\
\hline
\end{tabular}

TABLE VII

$p$-VAlues For Welch's Periodogram Method Under DifFerent Window Sizes AND OVERLAPPING SAMPLES FOR THE UPPER SidEBAND With No FILTERING

\begin{tabular}{|c|c|c|c|c|c|c|}
\hline \multirow{2}{*}{$\begin{array}{l}\text { Window } \\
\text { size }\end{array}$} & \multirow{2}{*}{$\begin{array}{c}\text { Overlapping } \\
\text { Samples }\end{array}$} & \multirow{2}{*}{$\begin{array}{c}\text { Number of } \\
\text { Windows }\end{array}$} & \multicolumn{4}{|c|}{$(1+2 s) f_{o} \mathbf{p}$-value with no filtering, $\mathbf{F s}=\mathbf{1 0} \mathbf{~ k H z}$} \\
\hline & & & Rectangular & Hamming & Hanning & $\begin{array}{c}\text { Chebyschev } \\
(100 \mathrm{~dB})\end{array}$ \\
\hline 10,000 & 0 & 1 & 0.88 & 0.01 & $4.79 \mathrm{e}-22$ & $1.38 \mathrm{e}-22$ \\
\hline 9,500 & 9,000 & 2 & 0.58 & $0.50 \mathrm{e}-02$ & $3.65 \mathrm{e}-23$ & $1.72 \mathrm{e}-22$ \\
\hline 9,000 & 8,500 & 3 & 0.73 & $0.24 \mathrm{e}-02$ & $5.46 \mathrm{e}-23$ & $2.30 \mathrm{e}-22$ \\
\hline 8,000 & 7,500 & 5 & 0.43 & $0.17 \mathrm{e}-02$ & $1.73 \mathrm{e}-22$ & $3.28 \mathrm{e}-22$ \\
\hline 7,000 & 6,500 & 7 & 0.65 & 0.01 & $3.01 \mathrm{e}-21$ & $4.06 \mathrm{e}-22$ \\
\hline 6,000 & 5,500 & 9 & 0.45 & 0.19 & $7.69 \mathrm{e}-17$ & $5.23 \mathrm{e}-22$ \\
\hline 5,000 & 4,500 & 11 & 0.03 & 0.77 & $1.28 \mathrm{e}-04$ & $8.17 \mathrm{e}-22$ \\
\hline 5,000 & 4,000 & 6 & 0.03 & 0.91 & $0.90 \mathrm{e}-02$ & $5.04 \mathrm{e}-22$ \\
\hline 5,000 & 2,500 & 3 & 0.03 & 0.99 & $0.39 \mathrm{e}-02$ & $1.18 \mathrm{e}-22$ \\
\hline 4,000 & 2,000 & 4 & $0.52 \mathrm{e}-02$ & 0.74 & 0.10 & $8.50 \mathrm{e}-20$ \\
\hline
\end{tabular}

TABLE VIII

$p$-Values For Welch's Periodogram Method Under Different Window Sizes and Overlapping SAMPLES FOR THE UPPER Sideband With No Filtering AND Fs $=200 \mathrm{~Hz}$

\begin{tabular}{|c|c|c|c|c|c|c|}
\hline \multirow{2}{*}{$\begin{array}{l}\text { Window } \\
\text { size }\end{array}$} & \multirow{2}{*}{$\begin{array}{c}\text { Overlapping } \\
\text { Samples }\end{array}$} & \multirow{2}{*}{$\begin{array}{c}\text { Number of } \\
\text { windows }\end{array}$} & \multicolumn{4}{|c|}{$(1+2 s) f_{o}$ p-value no filtering, $\mathbf{F s}=\mathbf{2 0 0} \mathbf{~ H z}$} \\
\hline & & & Rectangular & Hamming & Hanning & $\begin{array}{c}\text { Chebyschev } \\
(100 \mathrm{~dB})\end{array}$ \\
\hline 200 & 0 & 1 & 0.76 & 0.04 & $9.45 \mathrm{e}-23$ & $8.77 \mathrm{e}-23$ \\
\hline 180 & 160 & 2 & 0.58 & 0.01 & $5.25 \mathrm{e}-21$ & $1.57 \mathrm{e}-22$ \\
\hline 160 & 140 & 3 & 0.27 & $0.35 \mathrm{e}-02$ & $9.68 \mathrm{e}-19$ & $1.88 \mathrm{e}-22$ \\
\hline 140 & 120 & 4 & 0.42 & 0.01 & $3.90 \mathrm{e}-15$ & $2.09 \mathrm{e}-22$ \\
\hline 120 & 100 & 5 & 0.68 & 0.11 & $4.62 \mathrm{e}-10$ & $2.53 \mathrm{e}-22$ \\
\hline 100 & 80 & 6 & 0.05 & 0.87 & $0.66 \mathrm{e}-02$ & $4.18 \mathrm{e}-22$ \\
\hline 100 & 50 & 3 & 0.04 & 0.79 & $0.37 \mathrm{e}-02$ & $1.02 \mathrm{e}-22$ \\
\hline
\end{tabular}

10-kHz case, a Chebyschev $(100 \mathrm{~dB})$ window size of 5000 and an overlap of 4000 data samples generated a $p$-value of $2.81 \mathrm{e}-9$ (see Table IV); for the $200 \mathrm{~Hz}$ with notch filtering case, a Hanning window size of 100 and an overlap of 50 data samples generated a $p$-value of $2.39 \mathrm{e}-9$ (see Table VI). In addition, it is observed that for the lower sampling rate with notch filter case, all applied windows provided satisfactory results, whereas for the other two cases, the rectangular and Hamming windows were not adequate enough to suppress the main line frequency and thus decrease the spectral leakage.

Tables VII-IX depict the $p$-values for the Welch's periodogram method at the upper sideband for the three cases. Different from the lower sideband results, there was no observation showing that Welch's periodogram method improved the healthy-faulty discrimination when compared with the DTFT method in terms of yielding lower $p$-values. It is also seen that for the lower sampling rate with notch filter case, all applied windows worked well, providing lower $p$-values.
In Tables IV and VII, it is noticed that a Hanning window with a window size of 5000 and less generates poor $p$-values when compared with a Chebyschev $(100 \mathrm{~dB})$ window with the same window size. The $p$-values in Tables IV and VII correspond to the Welch's periodogram method with respect to the higher sampling rate with no filtering case. Fig. 15 illustrates the Welch's periodogram spectrum estimates for window sizes of 5000 and 10000 with the Hanning and Chebyschev $(100 \mathrm{~dB})$ windows. From Fig. 15, it is seen that as the window size decreases to 5000, some significant distortions occur around the main lobe with the Hanning window, which results from spectral leakage. The leakage problem has not been observed with the Chebyschev (100 dB) window at this window size.

\section{Feature Extraction Performance of Yule AR}

Table $\mathrm{X}$ depicts the $p$-values with respect to the Yule AR method at the lower and upper sidebands for the lower sampling 
TABLE IX

$p$-VAlues For Welch's Periodogram Method Under DifFerent Window Sizes ANd OVERLAPPing SAMPLES FOR THE UPPER SidEbAND With NOTCH FILTERING AND Fs $=200 \mathrm{~Hz}$

\begin{tabular}{|c|c|c|c|c|c|c|}
\hline \multirow{2}{*}{$\begin{array}{l}\text { Window } \\
\text { size }\end{array}$} & \multirow{2}{*}{$\begin{array}{c}\text { Overlapping } \\
\text { Samples }\end{array}$} & \multirow{2}{*}{$\begin{array}{l}\text { Number of } \\
\text { Windows }\end{array}$} & \multicolumn{4}{|c|}{$(1+2 s) f_{o} \mathbf{p}$-value with notch filtering $\left(r_{p}=0.91\right), \mathbf{F s}=200 \mathbf{H z}$} \\
\hline & & & Rectangular & Hamming & Hanning & $\begin{array}{c}\text { Chebyschev } \\
(100 \mathrm{~dB})\end{array}$ \\
\hline 150 & 0 & 1 & $1.30 \mathrm{e}-16$ & $4.84 \mathrm{e}-23$ & $9.89 \mathrm{e}-23$ & $2.95 \mathrm{e}-21$ \\
\hline 140 & 130 & 2 & $4.68 \mathrm{e}-21$ & $8.98 \mathrm{e}-23$ & $1.58 \mathrm{e}-22$ & $6.66 \mathrm{e}-21$ \\
\hline 130 & 120 & 3 & $3.46 \mathrm{e}-22$ & $1.07 \mathrm{e}-022$ & $2.97 \mathrm{e}-22$ & $1.19 \mathrm{e}-20$ \\
\hline 120 & 110 & 4 & $2.49 \mathrm{e}-22$ & $1.92 \mathrm{e}-22$ & $4.88 \mathrm{e}-22$ & $1.79 \mathrm{e}-20$ \\
\hline 110 & 100 & 5 & $4.38 \mathrm{e}-23$ & $2.41 \mathrm{e}-22$ & $7.35 \mathrm{e}-22$ & $2.21 \mathrm{e}-20$ \\
\hline 100 & 90 & 6 & $2.44 \mathrm{e}-22$ & $4.11 \mathrm{e}-22$ & $9.77 \mathrm{e}-22$ & $2.31 \mathrm{e}-20$ \\
\hline 100 & 50 & 2 & $1.95 \mathrm{e}-18$ & $6.70 e-23$ & $9.37 e-23$ & $3.03 \mathrm{e}-22$ \\
\hline
\end{tabular}

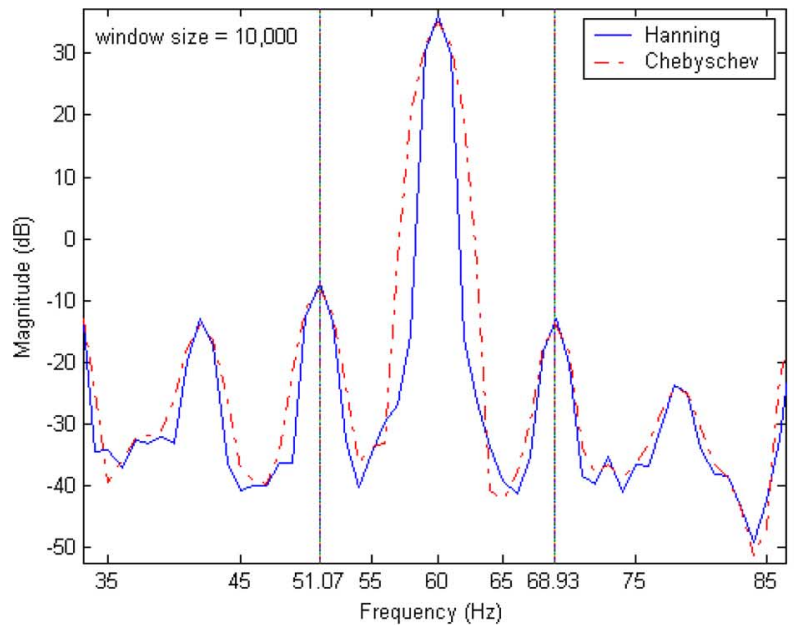

(a)

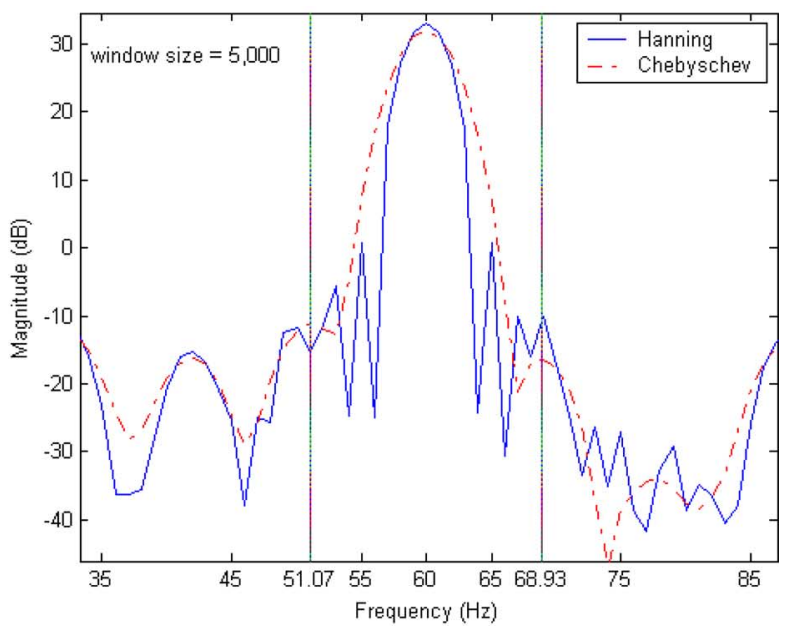

(b)

Fig. 15. Hanning and Chebyschev windows applied to Welch's periodogram method (Fs $=10 \mathrm{kHz})$. (a) Window size $=10000$. (b) Window size $=5000$.

TABLE $X$

$p$-Values With Respect to Yule AR for the Lower And Upper Sidebands (No Filtering, Fs $=200 \mathrm{~Hz}$ )

\begin{tabular}{|c|c|c|c|c|c|c|c|c|c|}
\hline & \multicolumn{10}{|c|}{ Model order } \\
\hline Sideband & $\mathbf{2 0}$ & $\mathbf{3 0}$ & $\mathbf{4 0}$ & $\mathbf{5 0}$ & $\mathbf{6 0}$ & $\mathbf{7 0}$ & $\mathbf{8 0}$ & $\mathbf{9 0}$ & $\mathbf{1 0 0}$ \\
\hline$(1-2 s) f_{o}$ & $0.11 \mathrm{e}-02$ & $0.13 \mathrm{e}-02$ & $0.29 \mathrm{e}-02$ & $0.48 \mathrm{e}-02$ & $0.54 \mathrm{e}-02$ & 0.01 & $0.62 \mathrm{e}-02$ & 0.02 & 0.01 \\
\hline$(1+2 s) f_{o}$ & 0.05 & 0.05 & 0.03 & 0.06 & 0.06 & 0.12 & 0.08 & 0.22 & 0.11 \\
\hline
\end{tabular}

TABLE XI

$p$-Values With Respect to Yule AR for the Lower Sideband (Notch Filtering, Fs $=200 \mathrm{~Hz}$ )

\begin{tabular}{|c|c|c|c|c|c|c|c|c|c|}
\hline Filter & \multicolumn{9}{|c|}{ Model order } \\
\hline$r_{p}$ & $\mathbf{2 0}$ & $\mathbf{3 0}$ & $\mathbf{4 0}$ & $\mathbf{5 0}$ & $\mathbf{6 0}$ & $\mathbf{7 0}$ & $\mathbf{8 0}$ & $\mathbf{9 0}$ & $\mathbf{1 0 0}$ \\
\hline $\mathbf{0 . 8 5}$ & $3.43 \mathrm{e}-04$ & $6.19 \mathrm{e}-08$ & $4.47 \mathrm{e}-07$ & $1.11 \mathrm{e}-05$ & $4.94 \mathrm{e}-06$ & $1.34 \mathrm{e}-05$ & $1.55 \mathrm{e}-05$ & $2.37 \mathrm{e}-05$ & $2.71 \mathrm{e}-06$ \\
\hline $\mathbf{0 . 8 7}$ & $2.92 \mathrm{e}-04$ & $8.01 \mathrm{e}-08$ & $5.59 \mathrm{e}-06$ & $1.55 \mathrm{e}-05$ & $2.27 \mathrm{e}-05$ & $1.74 \mathrm{e}-04$ & $9.59 \mathrm{e}-06$ & $1.03 \mathrm{e}-04$ & $2.42 \mathrm{e}-05$ \\
\hline $\mathbf{0 . 8 9}$ & $1.75 \mathrm{e}-04$ & $4.97 \mathrm{e}-06$ & $1.85 \mathrm{e}-05$ & $5.59 \mathrm{e}-07$ & $6.35 \mathrm{e}-06$ & $3.85 \mathrm{e}-05$ & $2.33 \mathrm{e}-04$ & $1.53 \mathrm{e}-04$ & $3.36 \mathrm{e}-05$ \\
\hline $\mathbf{0 . 9 1}$ & $2.42 \mathrm{e}-06$ & $3.26 \mathrm{e}-09$ & $3.72 \mathrm{e}-06$ & $1.80 \mathrm{e}-05$ & $2.21 \mathrm{e}-05$ & $4.97 \mathrm{e}-06$ & $8.82 \mathrm{e}-05$ & $1.41 \mathrm{e}-04$ & $5.98 \mathrm{e}-06$ \\
\hline $\mathbf{0 . 9 3}$ & $5.62 \mathrm{e}-06$ & $3.31 \mathrm{e}-05$ & $7.11 \mathrm{e}-05$ & $2.45 \mathrm{e}-06$ & $5.37 \mathrm{e}-06$ & $3.55 \mathrm{e}-05$ & $3.06 \mathrm{e}-04$ & $2.70 \mathrm{e}-04$ & 0.0018 \\
\hline $\mathbf{0 . 9 5}$ & $3.47 \mathrm{e}-04$ & $5.65 \mathrm{e}-04$ & $1.73 \mathrm{e}-04$ & $0.14 \mathrm{e}-02$ & $0.92 \mathrm{e}-02$ & 0.01 & 0.08 & 0.02 & $\mathrm{X}$ \\
\hline $\mathbf{0 . 9 7}$ & 0.33 & 0.07 & 0.15 & 0.19 & 0.18 & $\mathrm{X}$ & $\mathrm{X}$ & $\mathrm{X}$ & $\mathrm{X}$ \\
\hline
\end{tabular}

rate with no filtering case. From Table $\mathrm{X}$, it is seen that no useful classification is possible without suppressing the dominant main line frequency because all the yielded $p$-values had large values, indicating a poor classification performance.

Table XI depicts the $p$-values with respect to the Yule AR method at the lower sideband for the lower sampling rate with notch filtering case. In Table XI, the $p$-values correspond to different combinations of model orders and pole radius of notch filters. It is observed that a $p$-value as low as $3.26 \mathrm{e}-9$ is obtained with $r_{p}=0.91$ and model order $=30$ (highlighted in Table XI). Similarly, Table XII depicts the $p$-values with respect to the Yule AR method at the upper sideband for the lower sampling rate with notch filtering case. It is examined that a $p$-value of $5.70 \mathrm{e}-22$ has been obtained with $r_{p}=0.85$ and model order $=90$ (highlighted in Table XII). The "X" marks in Tables XI and XII indicate that the Yule AR spectrum cannot 
TABLE XII

$p$-VAlues With Respect to Yule AR For the UpPer Sideband (Notch Filtering, Fs $=200 \mathrm{~Hz}$ )

\begin{tabular}{|c|c|c|c|c|c|c|c|c|c|}
\hline Filter & \multicolumn{9}{|c|}{ Model order } \\
\hline$r_{p}$ & $\mathbf{2 0}$ & $\mathbf{3 0}$ & $\mathbf{4 0}$ & $\mathbf{5 0}$ & $\mathbf{6 0}$ & $\mathbf{7 0}$ & $\mathbf{8 0}$ & $\mathbf{9 0}$ & $\mathbf{1 0 0}$ \\
\hline $\mathbf{0 . 8 5}$ & $9.07 \mathrm{e}-17$ & $2.11 \mathrm{e}-15$ & $2.57 \mathrm{e}-19$ & $1.77 \mathrm{e}-17$ & $3.20 \mathrm{e}-18$ & $9.54 \mathrm{e}-19$ & $1.63 \mathrm{e}-20$ & $5.70 \mathrm{e}-22$ & $2.23 \mathrm{e}-19$ \\
\hline $\mathbf{0 . 8 7}$ & $1.14 \mathrm{e}-17$ & $3.86 \mathrm{e}-13$ & $1.14 \mathrm{e}-20$ & $1.73 \mathrm{e}-19$ & $2.73 \mathrm{e}-20$ & $2.95 \mathrm{e}-20$ & $9.56 \mathrm{e}-19$ & $2.10 \mathrm{e}-19$ & $2.35 \mathrm{e}-18$ \\
\hline $\mathbf{0 . 8 9}$ & $3.14 \mathrm{e}-15$ & $1.69 \mathrm{e}-13$ & $1.32 \mathrm{e}-18$ & $1.55 \mathrm{e}-16$ & $4.86 \mathrm{e}-21$ & $2.64 \mathrm{e}-17$ & $2.95 \mathrm{e}-17$ & $1.77 \mathrm{e}-15$ & $2.48 \mathrm{e}-15$ \\
\hline $\mathbf{0 . 9 1}$ & $7.24 \mathrm{e}-13$ & $5.49 \mathrm{e}-16$ & $3.91 \mathrm{e}-15$ & $9.14 \mathrm{e}-17$ & $5.22 \mathrm{e}-16$ & $2.65 \mathrm{e}-16$ & $1.40 \mathrm{e}-17$ & $4.11 \mathrm{e}-16$ & $9.67 \mathrm{e}-16$ \\
\hline $\mathbf{0 . 9 3}$ & $1.22 \mathrm{e}-13$ & $6.24 \mathrm{e}-16$ & $2.74 \mathrm{e}-19$ & $7.88 \mathrm{e}-20$ & $8.14 \mathrm{e}-19$ & $3.46 \mathrm{e}-19$ & $2.06 \mathrm{e}-18$ & $2.16 \mathrm{e}-17$ & $1.77 \mathrm{e}-16$ \\
\hline $\mathbf{0 . 9 5}$ & $3.52 \mathrm{e}-13$ & $6.30 \mathrm{e}-20$ & $9.50 \mathrm{e}-15$ & $1.27 \mathrm{e}-15$ & $7.10 \mathrm{e}-12$ & $2.56 \mathrm{e}-13$ & $3.37 \mathrm{e}-11$ & $4.23 \mathrm{e}-11$ & $\mathrm{X}$ \\
\hline $\mathbf{0 . 9 7}$ & $3.97 \mathrm{e}-04$ & $4.69 \mathrm{e}-04$ & $1.39 \mathrm{e}-04$ & $0.29 \mathrm{e}-02$ & $0.15 \mathrm{e}-02$ & $\mathrm{X}$ & $\mathrm{X}$ & $\mathrm{X}$ & $\mathrm{X}$ \\
\hline
\end{tabular}

be computed since the data length is smaller than the applied model order for these cases. With respect to Tables XI and XII, as the poles of the notch filter become closer to the unit circle, the impulse response of the filter becomes longer, and the length of the usable data becomes smaller. Thus, we obtain no results or poor $p$-values for these cases.

Before applying filtering, Yule AR results are useless because of not providing any information in terms of healthyfaulty discrimination, as can be seen from the large $p$-values depicted in Table X. After filtering, the dominance of the main line frequency is suppressed, and the sidebands are significantly isolated.

The decimation results indicate that a lower initial sampling rate can be used for broken rotor bar fault detection with DTFT and Welch's periodogram methods. It is the applied window function that makes a deep impact on the feature extraction performance with the nonparametric spectrum methods. For example, applying a rectangular window without notch filtering of the motor current data generates misleading results both for the DTFT and Welch's periodogram methods. There is no need for filtering with the DTFT and Welch's periodogram methods if a window function that can significantly reduce the spectral leakage effects is applied. To apply the Yule AR method for broken rotor bar detection, the dominance of the main line frequency must be suppressed. Otherwise, the sidebands of interest cannot be extracted, even if high model orders are used. The suppression of the main line frequency and isolation of the sidebands can be performed by applying a second-order notch filter. After notch filtering, Yule AR can be successfully applied and provide accurate healthy-faulty discrimination as the DTFT and Welch's periodogram methods.

In this paper, the digital notch filter design is performed under the assumption that the induction motor runs under a fixed main line frequency $(60 \mathrm{~Hz})$. For inverter-driven induction motors, where the fundamental frequency is not fixed but varies according to the variable-frequency drive to yield the desired motor torque or motor speed, the fixed-frequency notch filter is not applicable since the fundamental frequency is not anymore constant at $60 \mathrm{~Hz}$. To cope with the varying fundamental frequency, the digital notch filter parameters need to be adjusted according to the varying fundamental frequency. The digital filter has an advantage to be used in this case since it is easy to detect the fundamental frequency and change the notch filter parameters accordingly with digital filters.

\section{CONCLUSION}

This paper has used experimental results to illustrate that a digital notch filter design combined with a lower sampling rate can be successfully applied with the DTFT and AR-based spectrum methods for the broken bar detection problem. The utilization of a lower sampling rate is significantly important because a lower sampling rate means less computation and low cost in implementation, which could lead to more effective and less costly embedded system designs for motor condition monitoring applications.

\section{REFERENCES}

[1] M. E. H. Benbouzid and G. B. Kliman, "What stator current processing based technique to use for induction motor rotor faults diagnosis?" IEEE Power Eng. Rev., vol. 22, no. 8, p. 62, Aug. 2002.

[2] S. Bachir, S. Tnani, J.-C. Trigeassou, and G. Champenois, "Diagnosis by parameter estimation of stator and rotor faults occurring in induction machines," IEEE Trans. Ind. Electron., vol. 53, no. 3, pp. 963-973, Jun. 2006.

[3] S. H. Kia, H. Henao, and G.-A. Capolino, "A high-resolution frequency estimation method for three-phase induction machine fault detection," IEEE Trans. Ind. Electron., vol. 54, no. 4, pp. 2295-2304, Aug. 2007.

[4] H. Su and K. T. Chong, "Induction machine condition monitoring using neural network modeling," IEEE Trans. Ind. Electron., vol. 54, no. 1, pp. 241-249, Feb. 2007.

[5] S. Rajagopalan et al., "Analytic-wavelet-ridge-based detection of dynamic eccentricity in brushless direct current (BLDC) motors functioning under dynamic operating conditions," IEEE Trans. Ind. Electron., vol. 54, no. 3, pp. 1410-1419, Jun. 2007.

[6] B. Ayhan, M. Chow, and M. Song, "Multiple discriminant analysis and neural-network-based monolith and partition fault-detection schemes for broken rotor bar in induction motors," IEEE Trans. Ind. Electron., vol. 53 , no. 4, pp. 1298-1308, Aug. 2006.

[7] S. Bachir, S. Tnani, J. Trigeassou, and G. Champenois, "Diagnosis by parameter estimation of stator and rotor faults occurring in induction machines," IEEE Trans. Ind. Electron., vol. 53, no. 3, pp. 963-973, Jun. 2006.

[8] M. Haji and H. A. Toliyat, "Pattern recognition-A technique for induction machines rotor broken bar detection," IEEE Trans. Energy Convers., vol. 16, no. 4, pp. 312-317, Dec. 2001

[9] S. Nandi and H. A. Toliyat, "Condition monitoring and fault diagnosis of electrical machines," in Conf. Rec. 34th IAS Annu. Meeting, 1999, vol. 1, pp. 197-204.

[10] A. R. Mohanty and C. Kar, "Fault detection in a multistage gearbox by demodulation of motor current waveform," IEEE Trans. Ind. Electron. vol. 53, no. 4, pp. 1285-1297, Jun. 2006.

[11] J.-H. Jung, J.-J. Lee, and B.-H. Kwon, "Online diagnosis of induction motors using MCSA," IEEE Trans. Ind. Electron., vol. 53, no. 6, pp. 1842-1852, Dec. 2006

[12] M. E. H. Benbouzid, M. Vieira, and C. Theys, "Induction motors' faults detection and localization using stator current advanced signal processing techniques," IEEE Trans. Power Electron., vol. 14, no. 1, pp. 14-22, Jan. 1999.

[13] J. A. Antonino et al., "Validation of a new method for the diagnosis of rotor bar failures via wavelet transform in industrial induction machines," IEEE Trans. Ind. Appl., vol. 42, no. 4, pp. 990-996, Jul./Aug. 2006 
[14] K. D. Hurst and T. G. Habetler, "A comparison of spectrum estimation techniques for sensorless speed detection in induction machines," IEEE Trans. Ind. Appl., vol. 33, no. 4, pp. 898-905, Jul./Aug. 1997.

[15] F. Cupertino et al., "Comparison of spectral estimation techniques applied to induction motor broken bars detection," in Proc. SDEMPED, Atlanta, GA, Aug. 24-26, 2003, pp. 129-134.

[16] G. B. Kliman et al., "Non-invasive detection of broken rotor bars in operating induction motors," IEEE Trans. Energy Convers., vol. 3, no. 4, pp. 873-879, Dec. 1988.

[17] W. T. Thomson and I. D. Stewart, "On-line current monitoring for fault diagnosis in inverter fed induction motors," in Proc. IEE 3rd Int. Conf. Power Electron. Drives, London, U.K., 1988, pp. 432-435.

[18] F. Filipetti et al., "AI techniques in induction machines diagnosis including the speed rifle effect," in Conf. Rec. 34th IAS Annu. Meeting, San Diego, CA, Oct. 6-10, 1996, pp. 655-662.

[19] N. M. Elkasabgy, A. R. Eastham, and G. E. Dawson, "Detection of broken bars in the cage rotor on an induction machine," IEEE Trans. Ind. Appl., vol. 22, no. 6, pp. 165-171, Jan./Feb. 1992.

[20] G. Didier et al., "Rotor cage fault detection in induction motor using global modulation index on the instantaneous power spectrum," in Proc. SDEMPED, Atlanta, GA, Aug. 24-26, 2003, pp. 104-109.

[21] S. M. Kay and S. L. Marple, "Spectrum analysis-A modern perspective," Proc. IEEE, vol. 69, no. 11, pp. 1380-1419, Nov. 1981.

[22] S. L. Marple, Digital Spectral Analysis With Applications. Englewood Cliffs, NJ: Prentice-Hall, 1987.

[23] D. C. Montgomery, G. C. Runger, and N. F. Hubele, Engineering Statistics. New York: Wiley, 1999.

[24] M. Hayes, Statistical Digital Signal Processing and Modeling. New York: Wiley, 1996.

[25] F. F. Costa et al., "Improving the signal data acquisition in condition monitoring of electrical machines," IEEE Trans. Instrum. Meas., vol. 53, no. 4, pp. 1015-1019, Aug. 2004.

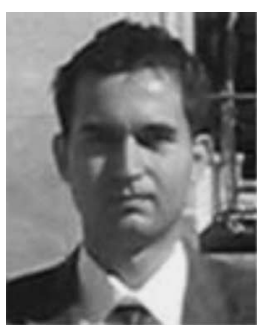

Bulent Ayhan (S'01-M'06) received the B.S. and M.S. degrees in electrical and electronics engineering from Bogazici University, Istanbul, Turkey, in 1998 and 2000, respectively, and the Ph.D. degree from North Carolina State University, Raleigh, in 2006.

His research interests include intelligent condition monitoring of rotating machinery systems.

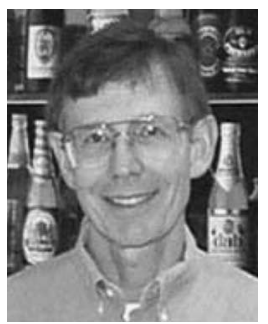

H. Joel Trussell (S'75-M'76-SM'91-F'94) received the B.S. degree from Georgia Institute of Technology, Atlanta, in 1967, the M.S. degree from Florida State University, Tallahassee, in 1968, and the Ph.D. degree from the University of New Mexico, Albuquerque, in 1976.

He joined the Los Alamos Scientific Laboratory, Los Alamos, NM, in 1969, where he began working in the image and signal processing in 1971. During 1978-1979, he was a Visiting Professor with HeriotWatt University, Edinburgh, U.K., where he worked with both the university and with industry on image processing problems. In 1980, he joined the Department of Electrical and Computer Engineering, North Carolina State University, Raleigh, where he currently serves as a Professor and the Director of Graduate Programs. During 1988-1989, he was a Visiting Scientist with Eastman Kodak Company, Rochester, NY. During 1997-1998, he was a Visiting Scientist with Color Savvy Systems, Springboro, OH. His research has been in estimation theory, signal and image restoration, and color image capture and reproduction.

Prof. Trussell was a member and past Chairman of the Image and Multidimensional Digital Signal Processing Committee of the IEEE Signal Processing Society. He was elected and served on the Board of Governors of the IEEE Signal Processing Society in 1994-1997. He is a past Associate Editor of the IEEE Transactions on ACoustics, SPEech, and Signal Processing (ASSP) and the IEEE Signal Processing LetTers. He is currently the Chairman of the Eastern North Carolina Chapter of the IEEE Signal Processing Society. He was a corecipient of the IEEE ASSP Society Senior Paper Award (with M.R. Civanlar) in 1986 and the IEEE-SP Society Paper Award (with P. L. Combettes) in 1993

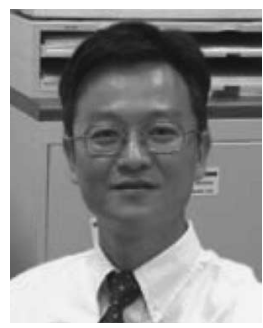

Mo-Yuen Chow (S'81-M'82-SM'93-F'07) received the B.S. degree in electrical and computer engineering from the University of Wisconsin-Madison in 1982 and the M.Eng. and Ph.D. degrees from Cornell University, Ithaca, NY, in 1983 and 1987, respectively.

He joined the Department of Electrical and Computer Engineering, North Carolina State University, Raleigh, as an Assistant Professor in 1987. He became an Associate Professor in 1993 and has been a Professor since 1999. He has established the Advanced Diagnosis, Automation and Control Laboratory at North Carolina State University. He was a Senior Research Scientist with the TACOM TARDEC Division, U.S. Army, during the Summer of 2003. In 1995, he spent his sabbatical leave as a Visiting Scientist with ABB Automated Distribution Division. He is the author or coauthor of more than 100 papers published in international journals and conference proceedings and is the author of one book and five book chapters. His research focuses on diagnosis, control, and computational intelligence. He has been applying his research to areas including mechatronics, motors, power distribution systems, network-based distributed control systems, and robotics.

Prof. Chow is the Vice President for Publication of the IEEE Industrial Electronics Society. He was the General Chair of the 31st Annual Conference of the IEEE Industrial Electronics Society (IECON05). He currently serves as an Associate Editor of the IEEE TRANSACTIONS ON INDUSTRIAL ELECTRONICS. He served as a Guest Editor of the IEEE TRANSACTIONS ON INDUSTRIAL ELECTRONICS special sections on Application of Intelligent Systems to Industrial Electronics in 1993, on Motor Fault Detection and Diagnosis in 2000, and on Distributed Network-Based Control Systems and Applications in 2003. He was the recipient of the IEEE Eastern North Carolina Section Outstanding Engineering Educator Award and the IEEE Region-3 Joseph M. Biedenbach Outstanding Engineering Educator Award.

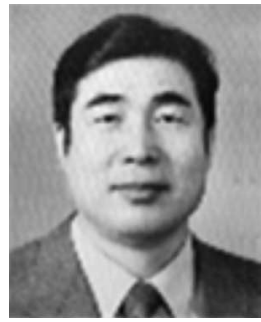

Myung-Hyun Song (M'95) was born Jeju, Korea, in 1953. He received the B.S., M.S., and Ph.D. degrees in electrical engineering from Korea University, Seoul, Korea.

Since 1988, he has been a Professor with the Department of Electrical Control Engineering, School of Information and Communication Engineering, Sunchon National University, Cheonnam, Korea. From 1977 to 1981, he was with Samsung Electronic Co., Suwon, Korea, where he worked in the design and application of electric motor. His current research interests include induction motor fault detection and diagnosis, factory automation, and web-based control. 